\title{
Evaluation of Risk Acceptance Criteria for Transporting Hazardous Materials
}

Transportation

Federal Railroad

Administration

Office of Research,

Development

and Technology

Washington, DC 20590

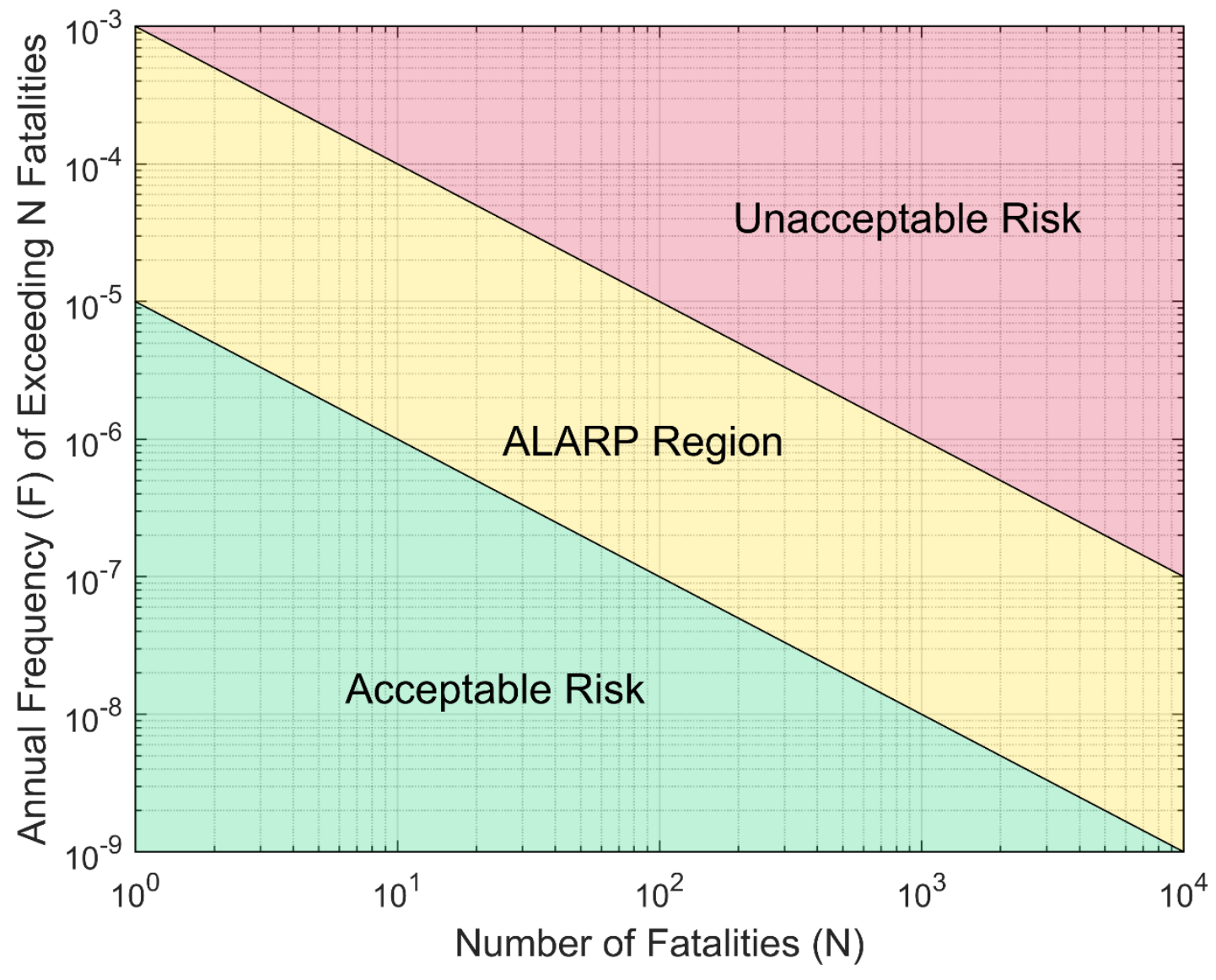

DOT/FRA/ORD-20/06 


\section{NOTICE}

This document is disseminated under the sponsorship of the Department of Transportation in the interest of information exchange. The United States Government assumes no liability for its contents or use thereof. Any opinions, findings and conclusions, or recommendations expressed in this material do not necessarily reflect the views or policies of the United States Government, nor does mention of trade names, commercial products, or organizations imply endorsement by the United States Government. The United States Government assumes no liability for the content or use of the material contained in this document.

\section{NOTICE}

The United States Government does not endorse products or manufacturers. Trade or manufacturers' names appear herein solely because they are considered essential to the objective of this report. 


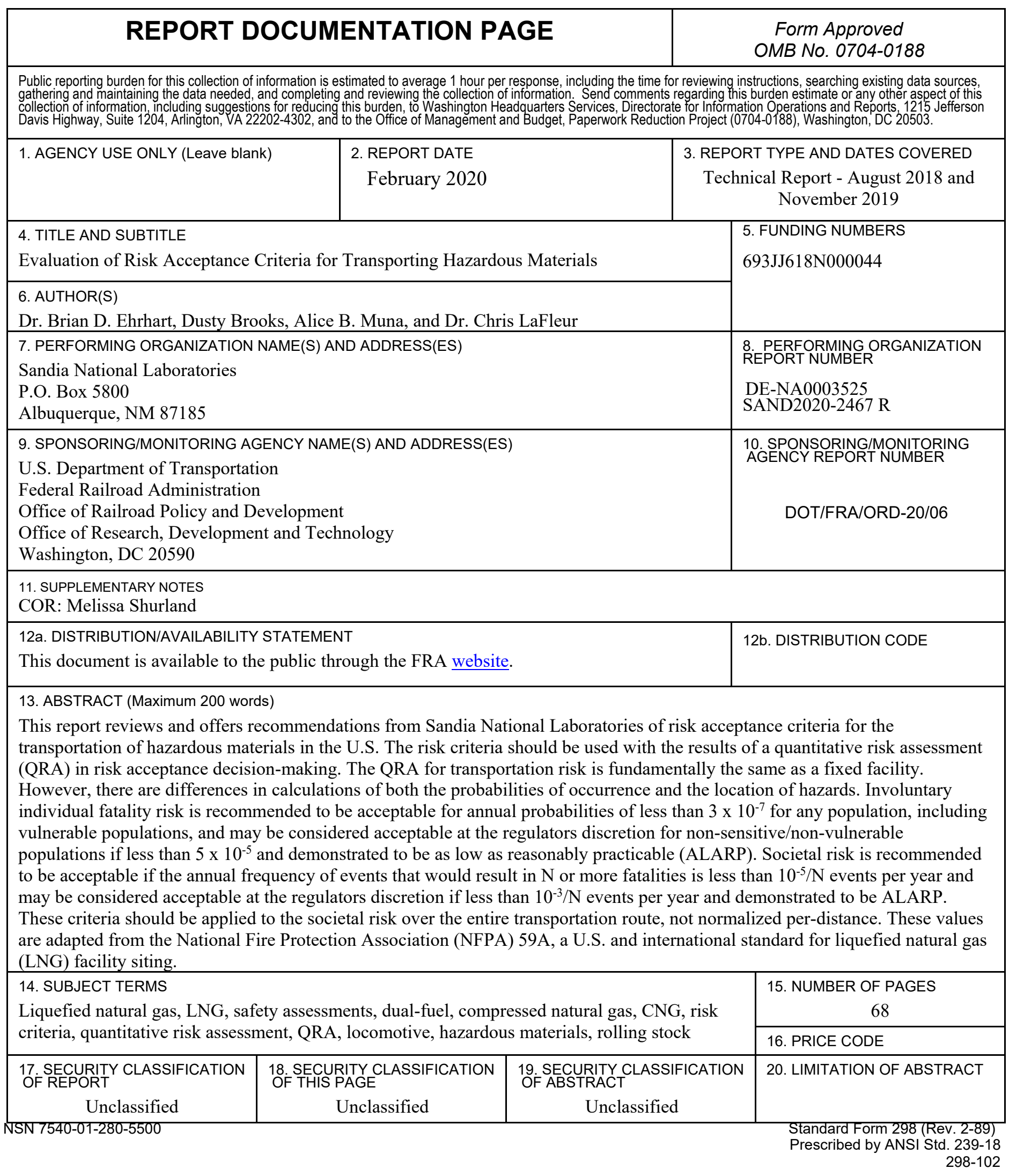




\section{METRIC/ENGLISH CONVERSION FACTORS}

ENGLISH TO METRIC LENGTH (APPROXIMATE)

1 inch (in) $=2.5$ centimeters $(\mathrm{cm})$

1 foot $(\mathrm{ft})=30$ centimeters $(\mathrm{cm})$

1 yard $(y d)=0.9$ meter $(\mathrm{m})$

1 mile $(\mathrm{mi})=1.6$ kilometers $(\mathrm{km})$
METRIC TO ENGLISH

LENGTH (APPROXIMATE)

1 millimeter $(\mathrm{mm})=0.04$ inch $(\mathrm{in})$

1 centimeter $(\mathrm{cm})=0.4$ inch $($ in)

1 meter $(\mathrm{m})=3.3$ feet $(\mathrm{ft})$

1 meter $(\mathrm{m})=1.1$ yards $(\mathrm{yd})$

1 kilometer $(\mathrm{km})=0.6 \mathrm{mile}(\mathrm{mi})$
AREA (APPROXIMATE)

1 square inch $\left(\mathrm{sq}\right.$ in, $\left.\mathrm{in}^{2}\right)=6.5$ square centimeters $\left(\mathrm{cm}^{2}\right)$

1 square foot $\left(\mathrm{sq} \mathrm{ft}, \mathrm{ft}^{2}\right)=0.09$ square meter $\left(\mathrm{m}^{2}\right)$

1 square yard ( $\left.\mathrm{sq} \mathrm{yd}, \mathrm{yd}^{2}\right)=0.8$ square meter $\left(\mathrm{m}^{2}\right)$

1 square mile $\left(\mathrm{sq} \mathrm{mi}, \mathrm{mi}^{2}\right)=2.6$ square kilometers $\left(\mathrm{km}^{2}\right)$

1 acre $=0.4$ hectare $($ he $)=4,000$ square meters $\left(\mathrm{m}^{2}\right)$

\begin{tabular}{|c|c|c|}
\hline $\begin{array}{r}\text { MASS - WEIC } \\
1 \text { ounce (oz) } \\
1 \text { pound (Ib) } \\
1 \text { short ton }=2,000 \text { pounds } \\
(\mathrm{lb})\end{array}$ & $\begin{array}{l}\text { HT (APPROXIMATE) } \\
=28 \text { grams }(\mathrm{gm}) \\
=0.45 \text { kilogram }(\mathrm{kg}) \\
=0.9 \text { tonne }(\mathrm{t})\end{array}$ & 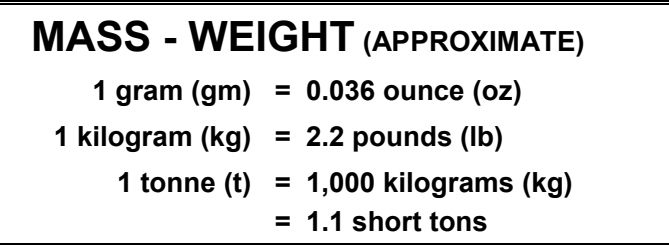 \\
\hline \multicolumn{2}{|c|}{ VOLUME (APPROXIMATE) } & VOLUME (APPROXIMATE) \\
\hline 1 teaspoon (tsp) & $=5$ milliliters $(\mathrm{ml})$ & 1 milliliter $(\mathrm{ml})=0.03$ fluid ounce $(\mathrm{fl} \mathrm{oz})$ \\
\hline 1 tablespoon (tbsp) & $=15$ milliliters $(\mathrm{ml})$ & 1 liter $(\mathrm{I})=2.1$ pints $(\mathrm{pt})$ \\
\hline 1 fluid ounce ( $\mathrm{fl} \mathrm{oz}$ ) & $=30$ milliliters $(\mathrm{ml})$ & 1 liter $(I)=1.06$ quarts $(q t)$ \\
\hline $1 \operatorname{cup}(c)$ & $=0.24$ liter $(\mathrm{I})$ & 1 liter $(I)=0.26$ gallon (gal) \\
\hline 1 pint (pt) & 0.47 liter (I) & \\
\hline 1 quart (qt) & 0.96 liter (I) & \\
\hline 1 gallon (gal) & 3.8 liters (I) & \\
\hline 1 cubic foot $\left(\mathrm{cu} \mathrm{ft}, \mathrm{ft}^{3}\right)$ & 0.03 cubic meter $\left(\mathrm{m}^{3}\right)$ & 1 cubic meter $\left(m^{3}\right)=36$ cubic feet $\left(\mathrm{cu} \mathrm{ft}, \mathrm{ft}^{3}\right)$ \\
\hline 1 cubic yard (cu yd, $\mathrm{yd}^{3}$ ) & $=0.76$ cubic meter $\left(\mathrm{m}^{3}\right)$ & 1 cubic meter $\left(\mathrm{m}^{3}\right)=1.3$ cubic yards $\left(\mathrm{cu} y d, \mathrm{yd}^{3}\right)$ \\
\hline \multicolumn{2}{|c|}{$\begin{array}{c}\text { TEMPERATURE (EXACT) } \\
{[(\mathrm{x}-32)(5 / 9)]^{\circ} \mathrm{F}=\mathrm{y}^{\circ} \mathrm{C}}\end{array}$} & $\begin{array}{l}\text { TEMPERATURE (EXACT) } \\
{[(9 / 5) y+32]^{\circ} \mathrm{C}=x^{\circ} \mathrm{F}}\end{array}$ \\
\hline
\end{tabular}

\section{QUICK INCH - CENTIMETER LENGTH CONVERSION}

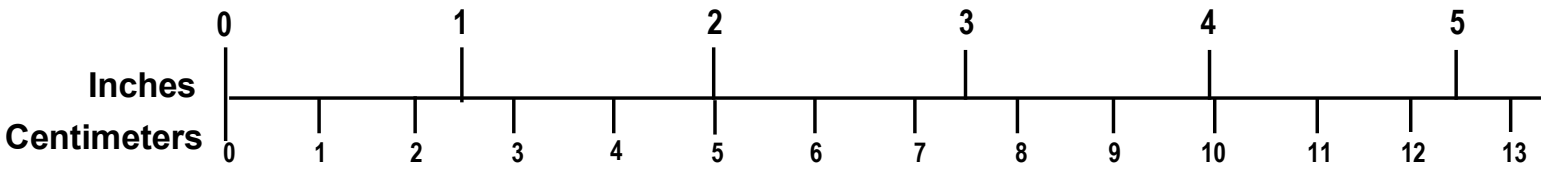

\section{QUICK FAHRENHEIT - CELSIUS TEMPERATURE CONVERSIO}

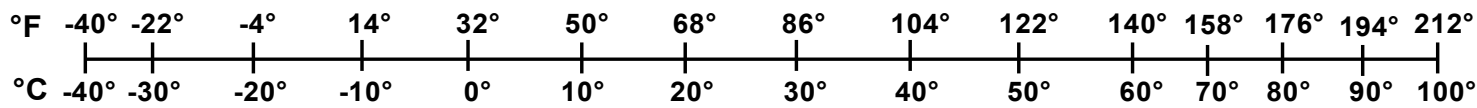

For more exact and or other conversion factors, see NIST Miscellaneous Publication 286, Units of Weights and Measures. Price \$2.50 SD Catalog No. C13 10286 


\section{Acknowledgements}

The authors wish to thank Dr. Phani Raj at the Federal Railroad Administration (FRA) for many detailed discussions and his review of this work. The authors also wish to thank the FRA Program Manager, Melissa Shurland, for contributing to this effort. ${ }^{1}$

${ }^{1}$ This report was prepared by Sandia National Laboratories. Sandia National Laboratories is a multimission laboratory managed and operated by National Technology \& Engineering Solutions of Sandia, LLC, a wholly owned subsidiary of Honeywell International Inc., for the U.S. Department of Energy's National Nuclear Security Administration. 


\section{Contents}

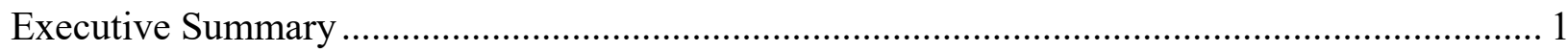

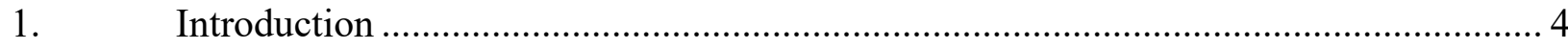

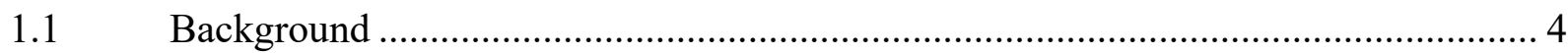

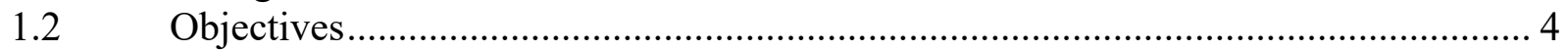

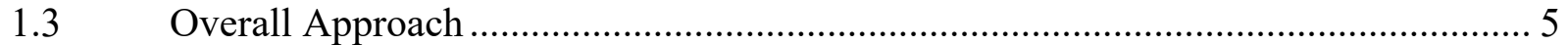

$1.4 \quad$ Scope

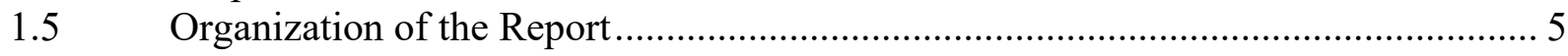

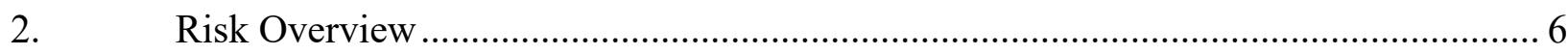

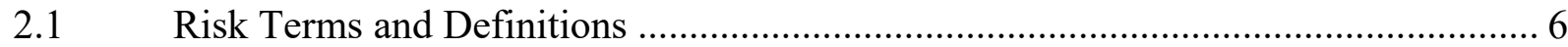

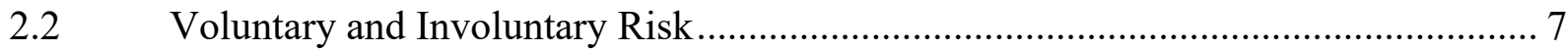

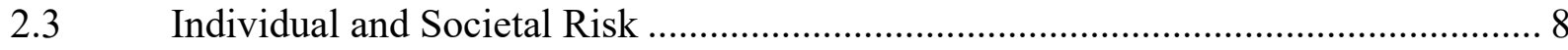

2.4 Fixed Facility Risk Compared to Transportation Risk ………............................... 10

2.5 Recommendations for Hazardous Materials, Including CNG and LNG, in Rail

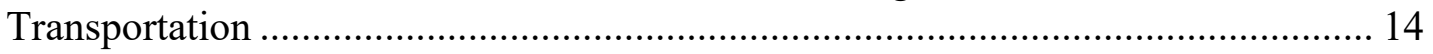

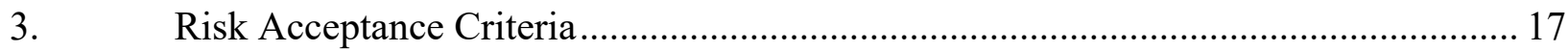

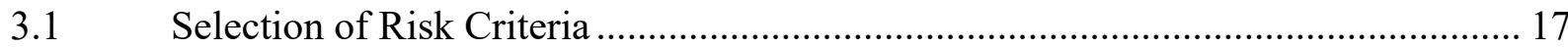

3.2 Summary of Applicable Risk Criteria Examples .................................................... 19

3.3 Proposed Risk Acceptance Criteria and Justification ............................................. 21

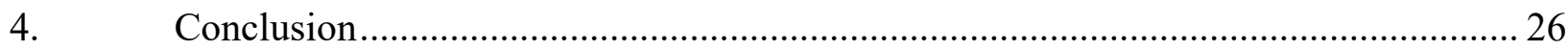

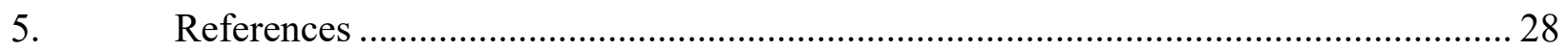

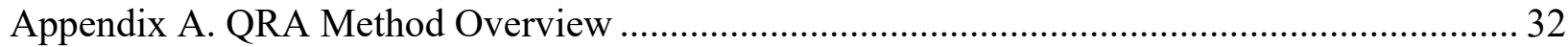

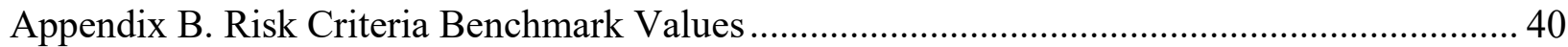

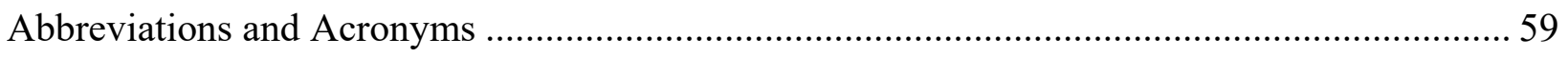




\section{Illustrations}

Figure 2-1. Acceptability regions of societal fatality risk in the F-N domain [8] .................... 10

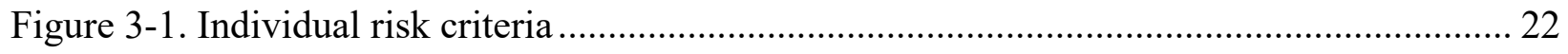

Figure 3-2. Summary of maximum acceptable societal risk criteria .................................... 24

Figure 3-3. NFPA 59A acceptability regions of societal fatality risk in the F-N domain [8] ...... 25 


\section{Tables}

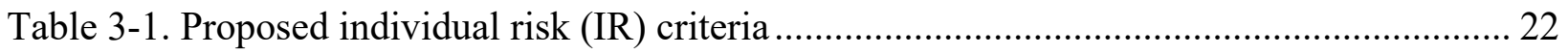




\section{Executive Summary}

From August 2018 to November 2019, the Federal Railroad Administration (FRA) funded research conducted by Sandia National Laboratories based on a literature review. This review established risk criteria and methods for assessing stationary facility risks and risks of transportation of hazardous materials by rail, road, or marine vessels. Specific focus was given to criteria and methods suitable for compressed natural gas (CNG) or liquefied natural gas (LNG) transported by rail. A risk methodology provides risk values that can be compared to risk criteria to determine whether a risk is acceptable or not. The risk values include a measure of likelihood (e.g., annual probability of a hazard occurring) and consequence (e.g., harm or fatality). These risk values are compared to risk criteria to make decisions about whether the risk is acceptable.

Based on the wide variety of risk methodologies surveyed and review of applications of these methods, it is recommended that a quantitative risk assessment (QRA) - rather than a semiquantitative or qualitative method - that includes the identification and evaluation of a comprehensive range of scenarios be used for CNG or LNG rail applications being considered by FRA. The QRA methodology must include route- and segment-specific characteristics to assess accident frequencies and population densities in the calculation of risk. The Dutch Purple Book - as well as other sources - is one example that details methods for the calculation of both societal and individual risks for both fixed facilities and transportation applications, including road, rail, and maritime. This methodology is widely accepted across many industries and has been implemented extensively in countries that have risk-based regulations, such as the United Kingdom (UK), Netherlands, Australia, Hong Kong, China, etc. In addition, off-the-shelf risk software such as software for the assessment of flammable, explosive and toxic impact (Safeti) and RISKCURVES exist that are based on the Dutch Purple Book methodology. This is not the only acceptable methodology, but it exemplifies features that define an acceptable QRA methodology.

Many aspects of a QRA methodology are very similar between an analysis for a fixed facility and for a transportation application. Fundamentally, a QRA examining fatality risk looks at the same outcome, regardless of exactly how an accident occurs. However, the specifics of how the risk is calculated will be different for these applications due to differences in the nature of the hazard for each application. As an example, the Dutch Purple Book methodology recommends quantifying transportation risk as a normalized value of the risk per kilometer of shipment. However, it is recommended that a total risk value for the entire route be used and not a normalized value for the evaluation of $\mathrm{CNG} / \mathrm{LNG}$ shipments on United States railroads. This recommendation is made because use of a normalized value could result in the risk from a long route being deemed acceptable and the risk from a shorter route being deemed unacceptable, even if the expected number of fatalities due to $\mathrm{CNG} / \mathrm{LNG}$ hazards on both routes is identical.

All formal approaches to selecting a risk criterion involve subjective factors and expert judgment to make a decision. Ideally, technical justification and consensus among regulatory agencies should also be included in the decision-making process. Transportation risk should consider the risks that can occur anywhere along the length of the route and enumerate from them an overall risk. However, in evaluating a fixed facility risk, impact to geography is generally more limited than for transportation. Risk acceptance criteria for both individual and societal risk are identified, particularly for transportation of hazardous of materials. Risk acceptance criteria from 
other countries and applications are discussed and provide a basis for understanding the level of risk accepted worldwide.

For involuntary individual fatality risk (IIFR) arising from shipments on rail of hazardous materials, including $\mathrm{CNG} / \mathrm{LNG}$, it is recommended that the following "acceptance" criteria be used to evaluate the involuntary individual fatality risks:

- Acceptable for all populations when IIFR is less than $3 \times 10^{-7}$ per year

- Unacceptable for sensitivity populations and places of public assembly (e.g., hospitals, schools, prisons, houses of worship, major event venues, etc.) when IIFR is above $3 \mathrm{x}$ $10^{-7}$ per year

- Unacceptable for all populations when IIFR is greater than $5 \times 10^{-5}$ per year

- Conditionally acceptable when the IFFR value is between $3 \times 10^{-7}$ per year and $5 \times 10^{-5}$ per year for non-sensitive populations if consensus can be reached after technical discussions between the project proponent and the regulator based on implementing risk reduction measures consistent with economic considerations that will reduce the risk to as low as reasonably practicable (ALARP).

To demonstrate that risk is ALARP, the proponent must show that the IIFR is as close as possible to the unconditional acceptance criterion $\left(3 \times 10^{-7}\right.$ per year) and further reduction of risk is not economically feasible. If this is demonstrated, decision-makers can decide whether adequate mitigations are in place and the risk is acceptable; approval should not be deemed as automatic.

The criteria values in this recommendation are the values prescribed for individual risk in the National Fire Protection Association (NFPA) 59A, which is a standard for siting of fixed LNG facilities. However, NFPA applies different automatic acceptance criteria based on population types; the lowest criterion is required for sensitive/vulnerable populations (e.g., schools, jails, etc.), but a higher criterion (less than $5 \times 10^{-5}$ ) is acceptable for non-sensitive/non-vulnerable populations. The recommendation here to use the NFPA 59A criteria for hazardous material transportation includes some modification. Instead, the recommended automatic acceptance criterion, less than $3 \times 10^{-7}$, is applied for both sensitive/vulnerable and non-sensitive/nonvulnerable populations. The recommendation also allows acceptance, at the regulators discretion, of IIFR greater than $3 \times 10^{-7}$ only for non-sensitive/non-vulnerable populations if the IIFR is less than $5 \times 10^{-5}$ and demonstrated to be ALARP. Essentially, the modification treats all populations as sensitive/vulnerable where practicable; there is no higher criterion below which IIFR for nonsensitive/non-vulnerable populations is automatically acceptable. This modification was made due to a release of hazardous material in a transportation scenario that would likely arise from a fast-developing scenario (e.g., derailment). Vulnerable/sensitive populations are typically treated differently at least in part due to the more limited ability to evacuate quickly away from a developing hazard, such as a leak developing at a facility. Transportation hazards are likely to develop much more quickly, so there is less benefit to be gained from evacuation.

Societal risk criteria incorporate the reality that accidents which affect large numbers of people are less common than those (i.e., more frequent accidents) that impact low numbers of people. The NFPA 59A societal fatality risk criteria are in the middle range of risk criteria examined across countries and industries. Like many of these criteria, it also recognizes that the annual frequency of large consequence events is smaller than that of smaller consequence events. In 
addition, the NFPA 59A societal risk values include an area for designating a range of risk values as acceptable if made ALARP. These criteria are a limit on unacceptable risk of annual frequency of events of $>10^{-3} / \mathrm{N}$ which will result in $\mathrm{N}$ or more fatalities, a limit of $<10^{-5} / \mathrm{N}$ events per year for acceptable risk, and a region in between the two for which risks should be shown to be ALARP and may not be automatically accepted. The NFPA 59A values already include an ALARP region, and this is kept in the recommendation due to the fast-developing nature of transportation hazards. However, an important distinction compared to some QRA methodologies (e.g., Dutch Purple Book) is that these proposed risk criteria should be applied to the calculated societal risk over the entire transportation route, and not evaluated (i.e., normalized) per-unit distance (i.e., kilometer or mile). This distinction is made to prevent the same expected frequency of fatalities from being deemed acceptable on a longer route but unacceptable on a shorter route. If the expected frequency of fatalities is normalized by track length to obtain risk, longer tracks could have lower normalized risk estimates than shorter tracks even if the tracks have an identical total frequency solely because of division by a larger number (i.e., longer track length).

As with any new technology, extensive historical data does not yet exist for the calculation of risk for $\mathrm{CNG} / \mathrm{LNG}$ for rail applications. Future efforts should include determining how to better estimate various aspects of the risk calculations, including mitigation measures to lower risk. The mitigation measures could include decreasing speed in more densely populated areas, decreasing the quantity of natural gas being transported, modifying the natural gas storage tanks, etc. 


\section{Introduction}

This report presents the results of research performed between August 2018 and November 2019 by Sandia National Laboratories on behalf of the Federal Railroad Administration (FRA) to review risk assessment methodologies and risk acceptance criteria related to the use of compressed natural gas (CNG) and liquefied natural gas (LNG) as fuel for locomotives, and bulk shipments as cargo. This report summarizes project activities, objectives, scope, and findings of a literature survey. A project conclusion is provided with recommendations for selecting a risk assessment methodology and risk acceptance criteria.

\subsection{Background}

Restrictive emissions requirements and historically low natural gas prices have resulted in efforts to develop a fleet of dual-fueled LNG/diesel hybrid locomotives. In addition, the Association of American Railroads (AAR) has petitioned the Pipeline and Hazardous Material Administration (PHMSA) to allow LNG to be shipped on rail in the U.S. Department of Transportation (DOT) 113 specification cryogenic tank car on rail as a commodity. FRA is the regulatory authority to approve shipments of LNG in portable tanks on rail as well as permitting the use of CNG/LNG tenders to fuel dual fuel locomotives. Therefore, FRA is interested in making scientifically defensible decisions on applications from stakeholders for use of CNG and LNG as locomotive fuel as well as shipment of CNG/LNG in portable tanks, such as T75 International Organization for Standardization (ISO) tank, consistent with FRA's mission of ensuring safety in the transportation of hazardous materials on rail. It is envisaged that safety/risk assessments provide such a scientific basis by considering a variety of conditions, situations, CNG/LNG properties and hazardous behavior, operational details and structural integrity of the vessels carrying $\mathrm{CNG} / \mathrm{LNG}$ in the analysis. As a result, FRA has contracted Sandia National Laboratories to review existing risk-based decision-making methodologies, in both United States and other regulatory jurisdictions worldwide, applicable to transportation of hazardous materials and identify well-accepted criteria for risk acceptance.

\subsection{Objectives}

The objectives of this project were to:

- Review and document the various risk acceptability criteria (i.e., for individual and societal risks, involuntary and voluntary risks) discussed in literature and implemented by regulatory or standards agencies, the world over, specifically applicable to transportation of hazardous materials

- Conduct a review of the fixed facility and transportation risk assessment methodologies used to calculate risk criteria that are relevant to hazardous material transportation- $\mathrm{CNG}$ and LNG, in particular - and identify common approaches. Highlight differences and key factors in methodologies.

- Provide recommendations on the best set of risk assessment criteria that can be used by FRA to support its decision on an application with which a risk assessment of the proposed hazardous materials transportation campaign is submitted by an applicant

- Provide recommendations on the best risk assessment methodology applicable to transportation risk assessment 


\subsection{Overall Approach}

First, literature was collected on risk assessment methodologies from publicly available sources. This initial research was focused on specific areas of interest, particularly related to transportation of hazardous materials. Risk acceptability criteria values were then researched which could be tied to the risk assessment methodology results. These initial results were presented to FRA to ensure that the objectives were met and documented in this report.

\subsection{Scope}

Qualitative risk assessment methodologies and criteria were not included in this report as calculation of societal and individual risks for regulatory decisions requires quantitative criteria. Qualitative measures of risk can lack objective results and do not allow safety to be compared against standard values.

\subsection{Organization of the Report}

This report is organized into four sections including two appendices. Section 1 introduces a discussion of the background, objectives, approach, and scope of the project. Section 2 provides an overview of different risk assessment concepts and terminology and evaluates transportation versus stationary facility risk assessment methodologies for risk quantification process. Section 3 summarizes the risk acceptability criteria from related industries currently used in the United States and other countries and provides a proposed risk acceptance criteria and justification. $\underline{\text { Section } 4}$ presents the conclusion and provides a recommendation for a risk assessment methodology and risk assessment criteria. Appendix A provides a quantitative risk assessment (QRA) overview, while Appendix B describes a literature search that was completed to explore examples of risk acceptability criteria to benchmark and provide context for the recommendations stated in the previous appendix. 


\section{Risk Overview}

This section provides an overview of risk and its characterization within a QRA framework, concluding with a recommendation on QRA methods for transportation of hazardous materials, including $\mathrm{CNG} / \mathrm{LNG}$.

\subsection{Risk Terms and Definitions}

Risk refers to the characterization of an undesired event as a combination of likelihood and consequence. Likelihood is a measure of how often the event is expected to occur (i.e., probability in a given time or frequency) and consequence is the negative outcome (e.g., fatality, injury, detrimental health effects, contamination, etc.) [1]. Both components of risk are essential for application of the concept in decision-making; a severe consequence may seem unacceptable if no measure of likelihood is included but can become acceptable if it is sufficiently unlikely. The framework for estimating the risk such that it can be compared to a criterion is QRA.

In the regulatory context, sufficiently low risk is defined based on a comparison of the estimated risk to a criterion or guideline that establishes an acceptable risk limit. Establishing risk guidelines is key to the utilization of any QRA methodology. This section presents different types of risk that can be examined in QRA analyses. The following sections discuss these categories further and summarize their application with respect to transportation.

Risk can be measured in different forms depending on the context in which the QRA is applied and the criterion/criteria used to define acceptable risk. For example, economic loss, human injury or fatality, or environmental damage can all be used to measure risk whenever those consequences are of concern and criteria can be established.

For risks related to $\mathrm{CNG} / \mathrm{LNG}$ transportation, the associated criteria could reflect acceptance levels for either injuries or fatalities. However, the discussion in this report focuses on the frequency of fatalities since that is typically the primary concern for a safety regulator or decision-maker. This is not to say that the risk of fatality alone would necessarily be the only criteria of interest; different metrics and measures can be used in conjunction with one another.

Applicable risk definitions from the American Institute of Chemical Engineers (AIChE) Center for Chemical Process Safety (CCPS) Process Safety Glossary are included here to define a common language for discussing risk acceptability criteria [2]:

Individual Risk: The risk to a single person near a hazard.

Societal Risk: The measure of risk to a group of people. It is most often expressed in terms of the frequency distribution of multiple-casualty events.

Voluntary Risk: Risk that is consciously tolerated by someone seeking to obtain the benefits of the activity that poses the risk.

Involuntary Risk: Risk that is imposed on someone who does not directly benefit from the activity that poses the risk.

Each of these risk measures is discussed in the following sections. 


\subsection{Voluntary and Involuntary Risk}

Voluntary and involuntary risk differ in the ability for the individual to choose whether to accept the risk. The type of risk associated with a hazard typically determines if restrictions are imposed to limit risk.

\subsubsection{Voluntary Risk}

Voluntary risk is where an individual willingly and knowingly undertakes an activity, such as a recreational activity or an occupational risk. Activities such as driving a car or skydiving are selfimposed and constitute examples of voluntary risk. The risk of the activity is known to the individual and the individual inherently accepts the risk based on their interests. Individuals can also choose when to partake in activities and adjust their personal exposure level to the hazards. For example, by choosing to not partake in skydiving, the hazard would be reduced to zero. Another example of voluntary risk is occupational position, which is an individual that chooses to partake in a hazardous activity for their own benefit. For example, an individual may accept a job in a hazardous location for an increased salary.

The potential consequences for voluntary risk are usually limited to the individuals choosing to partake in the risk. The society-at-large plays a limited role. However, there are instances of government intervention, typically through communicating the risk to the public (i.e., explaining the consequences of smoking). In doing so, the government helps individuals identify and understand the risks, but the government does not typically impose restrictions to undertaking the risk itself.

\subsubsection{Involuntary Risk}

Involuntary risk is where an individual has little or no choice or benefit in undertaking a risk. Involuntary risk is controlled by society in which the individual lives, through government agencies, political entities, or other authorities having jurisdiction. Typically, only a select group of individuals are fully aware of the criteria and options involved in making a risk decision, but their decisions could have wide-reaching impacts. The public may have little say in accepting a risk and providing feedback in a timely manner. An example of involuntary risk is an environmental hazard, such as air pollution, which could affect numerous individuals without their ability to mitigate the cause.

A characteristic of involuntary risk is that the risk cannot be reduced to zero. For example, a person could move away from a high pollution area and the risk to that person would be decreased, but the overall risk still exists for the population that is still exposed. The sources of involuntary risk are beyond the control of individuals, therefore involuntary risk is an issue for the public that the government plays a role in controlling and mitigating. For example, although an individual choosing to smoke a cigarette is voluntary, the secondhand smoke from the cigarette was found to cause cancers, thus becoming an involuntary risk to others. Therefore, Federal, State and local governments took a more proactive approach to addressing smoking in public places.

Involuntary risks are particularly relevant to a rail network, in which people are living or working near a rail line all along which the transportation of hazardous materials could pose potential hazards. An individual close to a transportation corridor is unlikely to derive any 
immediate and direct benefit from the transport of a hazardous material. Individuals can do little to directly mitigate any potential hazards to which they could be exposed.

Risk analysis is critical to decision making, and so policymakers should rely on an established, formulaic way of determining the involuntary risk to the public from a new hazard. Risk acceptance criteria for involuntary risks are generally lower than for voluntary risks, due to the involuntary nature of the imposed risk. Starr developed a method to analyze voluntary and involuntary risk and concluded that the public will accept voluntary risk levels that are approximately 1,000 times higher than involuntary risks [3]. Another way of stating this observation is that an acceptable involuntary risk magnitude should be, at least, a factor of 1,000 smaller than acceptable voluntary risk.

\subsection{Individual and Societal Risk}

In addition to distinguishing between voluntary and involuntary risk, QRA distinguishes between individual risk — which can be voluntary or involuntary — and societal risk - which is involuntary. The following sections describe individual and societal risk and how each is applied in risk analysis and regulation.

\subsubsection{Individual Risk}

Individual risk is used to analyze the risk posed to a single individual. Individual risk describes the probability of suffering a fatality or injury over a specified period of time (i.e., generally a year) by a specific hypothetical individual who could be exposed to a hazard at their geographic location.

One of the benefits of calculating individual risk is that it is simple to compare risk values between hazards or events. This ease of comparing individual risk values is why individual risk plays a major role in health and safety regulation. For example, the Nuclear Regulatory Commission (NRC) states that the probability of fatality to an average individual in the vicinity of a nuclear power plant due to a reactor accident should not exceed $5 \times 10^{-7}$ in a year [4]. Other examples of individual risk values, although there is no regulatory basis for them, include the probability of fatality to an individual traveling by air $\left(1.4 \times 10^{-5}\right.$ /year $)$, by road vehicle $(7.7 \mathrm{x}$ $10^{-5}$ /year) or by train $\left(2.5 \times 10^{-5}\right.$ /year) [5]. In this example, the individual risk values are higher than the regulatory values for the NRC. As discussed in Section 2.2, the public have a higher tolerance of risks from voluntary activities (i.e., traveling) than involuntary activities (i.e., living near a nuclear power plant). Analyzing the pattern of individual risk values can help to define the culture of risk acceptance criteria.

The specifics of how individual risk is evaluated can differ between QRA methods. Individual risks are often presented in the form of the likelihood of a fatality occurring to the individual and the time period over which the chance of fatality is prevalent. It is also possible to define individual risk in terms of injuries, but there is often less information available for injuries because the nature of injuries varies widely.

Individual risk measures can be analyzed by the following means:

- Individual risk contours that calculate the individual risk at every geographic location and assume that a person will be present and subject to the risk 100 percent of the time. 
- Individual risk assessment involves the calculation of the annual probability that an individual will suffer a fatality due to exposure to all hazards or activities during a given year that are relevant to the activity under assessment.

- Maximum individual risk is the individual risk to the person exposed to the highest risk in an exposed population (i.e., operator or person at the location with the highest risk).

- Other transportation-specific individual risk metrics could involve a distance, such as fatalities per passenger miles. However, this metric is more for passengers on the train, versus the risk to the exposed population surrounding the rail tracks.

Although individual risk can be calculated in several ways, it is most commonly expressed as an annual probability. The Health and Safety Commission in the United Kingdom published a series of average individual risks (AIR) for fatalities averaged over the entire population in 2001 [6]. The reported values include both voluntary (i.e., road accident) and involuntary hazards (i.e., lightning). Individual risk values ranged from $5.4 \times 10^{-8}$ to $2.6 \times 10^{-3}$, depending on the specific hazard. Though these are examples of compiled risk data and not regulatory limits, this shows that there is a substantial range of individual risk values that are generally accepted.

For hazards where there is little or no historical data, there are different ways to estimate the risk of postulated scenarios. For example, the Guidelines for Quantitative Risk Assessment (Dutch Purple Book) [7], published in the Netherlands, provides a standard for calculating varying types of risks and is widely used across many industries. In the Dutch Purple Book, individual risk is calculated at a single point by summing the contributions from the frequency of event outcomes (e.g., including conditional probabilities of occurrence of appropriate weather conditions, hazmat release conditions, hazardous behavior conditions, etc.).

Additionally, the Dutch Purple Book risk assessment methodology and the risk assessment methodology prescribed in NFPA 59A, Standard for the Production, Storage, and Handling of Liquefied Natural Gas for LNG stationary facilities both state that individual risk should be presented graphically, to show how risk is distributed over a geographic area [8].

\subsubsection{Societal Risk}

Societal risk measures the risk to a group of people. Societal risk calculations capture lowfrequency high-consequence events as well as high frequency but low consequence events. The low frequency-high consequence events may represent a small risk to an individual but could expose many people. There is often more of a public reaction for one event with multiple fatalities than multiple fatalities occurring from multiple events. For example, a single vehicular incident killing 10 people is considered to be worse than 10 fatalities occurring from 10 individual vehicle crashes. Societal risk is used to quantify the occurrence and consequence of these possible multiple-fatality events.

Societal risks are typically presented in the form of a diagram of cumulative annual frequency (F) of casualty exceedance versus the number $(\mathrm{N})$ of exposed population subject to the casualty (i.e., a F-N plot) [8]. An example societal risk curve from NFPA 59A is shown in Figure 2-1. The slope of the F-N curve is defined by a risk aversion factor that is designed to reflect society's aversion to single accidents with multiple fatalities as opposed to several accidents with few fatalities. 


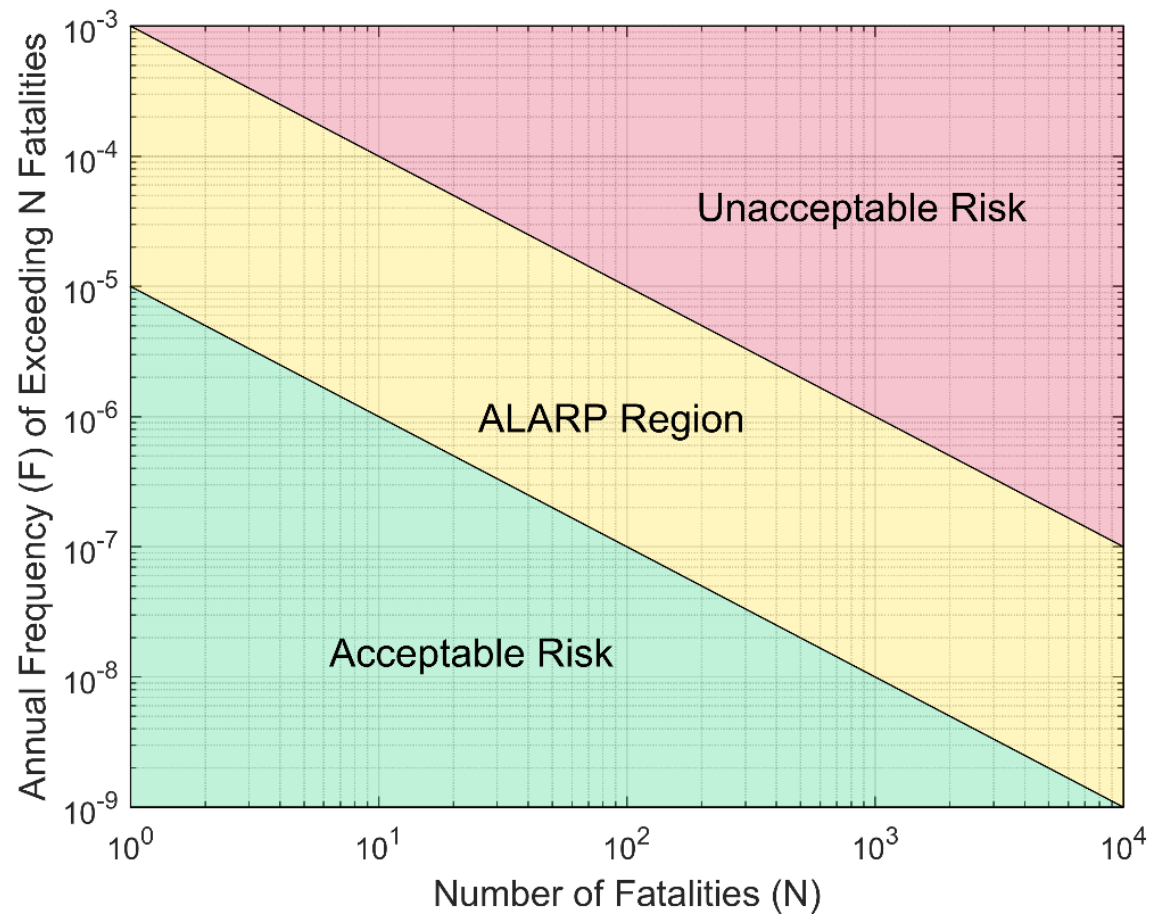

Figure 2-1. Acceptability regions of societal fatality risk in the F-N domain [8]

There is no distinction between involuntary and voluntary risk when analyzing societal risk because it is assumed that only involuntary risk is enumerated. This is especially pertinent when analyzing transportation risk over a distributed geographical area (i.e., railroad route) since there is less chance of the risk being voluntary. Societal risk calculations require defining the surrounding population. For transportation risk, this would consist of defining a population (i.e., density and its variation) surrounding a route. This definition could include the population characteristics (e.g., residential vs. industrial), the likelihood of a population nearby (e.g., stadium which fills up on weekends or industrial area where the population is smaller at night), and/or mitigation factors.

An example of a way to calculate societal risk can be found in the Dutch Purple Book which states that societal risk can be calculated from the expected number of fatalities for a point on a grid based on a hazardous material loss of containment event, weather class, wind direction, and ignition of the hazardous material. The Dutch Purple Book methodology requires determining the population surrounding a fixed facility or, for transportation risks, on the route selected. The expected number of fatalities in all grid cells is calculated and the cumulative annual frequency of having more than $\mathrm{N}$ deaths is determined. Consideration of multiple scenarios and grid cells results in a curve on the F-N plot, based on the number of scenarios which result in various numbers of fatalities; this curve can then be compared to the limit lines on the same plot.

\subsection{Fixed Facility Risk Compared to Transportation Risk}

Individual and societal risks related to hazardous materials are calculated with differing methodologies based on whether the hazardous materials are part of a fixed facility, such as an oil refinery, or are being transported from one place to another. However, the procedure for calculating risk values is similar regardless of fixed facility or the mode of transportation for 
individual and societal risk. This section provides a summary of the key factors and differences between the fixed facility and transportation risk methodologies that impact their applicability to the transportation risk of hazardous materials. This comparison is based on a literature search of published books and journal articles across a wide variety of industries for both fixed and mobile systems in several different countries. Methodologies were surveyed from transportation industries such as maritime [9, 10], rail [11-17], road transportation [18-23], and spacecraft [24, 25] as well as from stationary facilities such as nuclear power [26], chemical processing [27], space launch, military systems, and LNG facilities [8]. Methodologies prescribed by regulatory agencies and national government organizations were also included, such as, the Netherlands [7, 28], United Kingdom [29, 30], United States [31], Australia [32-34], Hong Kong, Sweden [35], Norway [36], Finland [37], the International Standards Organization [38], the International Maritime Organization [39-41], and the U.S. Nuclear Regulatory Commission [42, 43].

This section is organized according to some of the key steps of the general quantitative risk assessment method which are outlined in Appendix A.

\subsubsection{Scope Definition}

The units for the calculation of risk are defined within the scope definition task of most QRA methodologies surveyed. Key events that dominate the hazardous material-related QRA methodologies for both fixed and mobile systems are loss of containment, fires and explosions, boiling liquid evaporating vapor explosions (BLEVEs), and both accident and non-accident events. For fixed facilities, the nature of accident scenarios revolves around containment failures, system failures, or component failures. For transportation risks, the scenarios focus on accidents involving the mode of transportation (due to collision with other vehicles, irregular guideways, human error, weather causes, etc.) resulting in damage to the package or the container leading to the release of the contained hazardous material.

Loss of containment events are the focus of the QRA scope in nearly all cases for hazardous materials that are toxic, flammable, or harmful to the environment. In the nuclear industry, which has some of the most mature quantitative risk methods for fixed facilities, several major factors are included in the scope, including external events (e.g., plane crashes and natural disasters) and internal events (e.g., fires and loss of coolant water). The National Aeronautics and Space Administration (NASA) also has mature risk methods which cover space flight operations (i.e., transportation risks) through all operational phases, from pre-launch to space flight to reentry and recovery.

\subsubsection{Risk Calculation}

The goal of any QRA methodology is to obtain an estimate of risk regardless of whether the facility is stationary or the system is mobile, and the resulting risk values have common units such as probability per year of causing fatal harm to an individual at a specified location (individual risk) or an F-N curve (societal risk). To accomplish this, all QRA methodologies share some common features.

Risk is a measure of the effect of probabilities of occurrence of detrimental events and the consequence of such events. This effect is presented as the product of likelihood and consequence in many risk methods, including the industry standard Dutch Purple Book. It can also be presented as the likelihood of a consequence, or the frequency of a consequence.

Regardless of how the information is presented, the risk measure describes what can happen as 
the result of an accident and how likely that outcome is. In QRA methodologies, risk is estimated for each of the defined scenarios and the sum of these estimates defines the total risk. The individual scenario risks that define this sum are usually presented in the QRA with the total risk to communicate the relative contributions from each scenario to the overall risk. This equation for risk applies whether the risk of interest is individual or societal and the distinction between individual and societal risk depends on whether the number of individuals exposed to the risk is estimated.

For fixed facilities, it is sufficient to discretize the problem by scenarios and estimate risk for each scenario. For transportation risk, the estimation of risk can become much more complicated due to spatially-varying factors that contribute to the likelihood of an accident (e.g., guideway irregularities, other traffic, terrain, weather, maintenance, intersections, etc.) and the consequences (e.g., exposure of different population density regions). This may require further discretization of the transportation route into smaller, more homogenous segments for which the risk from a specific scenario can be estimated as in a fixed facility. The risks from each distinct segment are added over the entire route to define the total risk for the route.

\subsubsection{Define Scenarios}

The scenarios considered and included in most QRA methodologies vary widely across industries and correspond directly to the nature of the hazard presented by the system.

For stationary applications, the scenarios defined fall into three categories: 1) scenarios that damage the processes or property of the facility and harm employees or other people expected to be on site, 2) scenarios that have consequences severe enough to extend beyond the boundaries of the facility, and 3) scenarios that are initiated off site and impact the facility or operations. For internal events, scenarios are dominated by fires and explosions as well as toxic releases caused by events specific to the facility or industry.

For transportation systems, most scenarios focus on accidents involving the specific mode of transportation being studied. For example, the maritime industry's risk methodology focuses on the loss at sea of container and cargo ships. Likewise, the aviation industry methodology encompasses aircraft crashes while road transportation methods are dominated by traffic accidents and rollover events where the hazardous materials cargo is released. For transportation systems which occur in public spaces, such as road transport, no differentiation is made for scenarios which only impair the truck and its cargo (like category 1 above) and scenarios that impinge beyond the boundaries of the vessel or truck (category 2 above). Also, no differentiation is made for scenarios that are initiated due to a failure of the vessel or truck itself or a failure of an external object or other vessel or truck (as in category 3 above). For example, a gasoline tanker on the road can be in an accident caused by a failure of the brakes or caused by the failure of another driver failing to brake. Both causes are included as accidents causing a release and are not treated differently when analyzing the consequences.

\subsubsection{Consequence Evaluation}

Consequence can be quantified in terms of human losses (i.e., injuries, fatalities, and illnesses), or it can be quantified in terms of material or economic losses, such as property damage, remediation costs, and interruptions of business operations or supply chain movement. Consequence can also be quantified in terms of the physical characteristics of an undesirable event, for example, flame size, peak overpressure from explosions, or toxic vapor concentration. 
Quantification of these metrics assumes that they are highly correlated with the ultimate consequence of interest (e.g., fatalities and injuries). An example of this can be seen in the nuclear reactor industry. The NRC defines an objective that the quantified reactor core damage annual frequency for a site is below $1 \times 10^{-4}$. This is not a requirement. Other countries, such as Finland and France, impose a regulatory limit on core damage annual frequency of $1 \times 10^{-5}$ [44] . Whether it is an objective or a requirement, this metric does not exist to protect nuclear power plant operators from the economic consequences associated with core damage; it exists to protect the public from radiation dose even though the consequence being quantified is not dose to the public. Consequences should be quantified such that they are directly comparable to national requirements or guidance.

The methods used for quantification of consequence depend on many factors, which include the causal event(s), consequence metrics being estimated, and the problem physics. The overall concept for consequence evaluation is the same for stationary facilities and for transportation risk; a negative event is assumed to occur, and the impact of that event is estimated, usually using a combination of data, expert judgement, and physical models. The factors included in the quantification, however, can differ between stationary facilities and transportation.

For example, maritime risk assessments separate the risk into a component for the specific ship and another component for each route to obtain route-specific consequence estimates. The shipspecific component of risk does not vary spatially, but the route component does. This methodology allows decision-makers to understand the risk associated with any routing decision, but also requires sufficient data and a valid consequence model for each route. Similarly, risk assessments for transportation of hazardous materials can include routing models with population densities and other spatially varying parameters (i.e., meteorology, climate, terrain, etc.) that estimate consequences for different routes or for specific segments of a route.

Discretization of the transportation route is one method employed for transportation consequence evaluation. Essentially, the route being studied is subdivided into separate regions, each of which is then treated in the same manner as a fixed facility with its own fixed-but potentially uncertain — values for spatially-varying parameters like population density. The analysis is repeated for many fixed points or segments along the transportation route and the overall consequences must be understood as a compilation of these estimates.

Some industries estimate consequences at fixed facilities separately for workers and for general members of the public. This distinction makes sense for these facilities, since workers are typically closer to hazards than non-workers, and the concept of voluntary versus involuntary risk is addressed this way. The public has the involuntary risk based on their proximity to the facility and the worker represents the voluntary risk by choosing to work at the facility. For transportation risk, this may also be a logical distinction; workers on the transportation vehicles or at refueling stations are likely to be closer to the site of an accident than non-workers and may be subjected to higher consequences if an accident occurs. Separating the analysis for these two populations logically extends to transportation risk, wherein separate consequence calculations may be performed for stops as opposed to remote segments of transportation routes.

The notion of a maximally exposed individual is also a common method for quantifying consequence. Rather than estimate consequence for a population, the analysis estimates consequence for a single individual who is assumed to be in the most vulnerable condition during an accident. Use of the maximally exposed individual allows for some simplification of 
the analysis by assuming worst-case accident conditions rather than estimating the possible range of conditions or best estimates. However, this simplification also comes with a cost; the consequence for the maximally exposed individual may be unacceptably high, but this gives no information about the overall societal risk, which may be acceptable. Similarly, the consequences for a maximally exposed individual may be low, but if many people would be exposed to those consequences, the overall societal risk may be unacceptably high. The notion of a maximally exposed individual can be illustrative, but care is necessary to avoid obfuscating the understanding of societal risk.

\subsubsection{Likelihood Evaluation}

The likelihood component of risk is important to quantify so decision makers can correctly interpret the consequences of decisions. Airline travel is a common example of this concept. The consequences of an aircraft accident are severe; such accidents can, and do, result in hundreds of fatalities. Despite this, travel by air is a well-accepted mode of transportation because the likelihood is very low. Without the likelihood component of risk, airline travel would be viewed as too risky.

The likelihood estimate is often presented using probability, either as a single probability, a distribution that characterizes the uncertainty in the probability, or a range of probability values. It may also be time dependent (e.g., annual probability, lifetime probability) or estimated independently for different populations (e.g., workers, non-workers, adults, children, etc.). Similarly, the likelihood is also often presented as a frequency which expresses the expected number of events over a fixed period of time.

Where possible, the likelihood can be estimated using data. Again, airline travel is an excellent example. There are tens of thousands of flights per day in the continental United States alone, which allows for an accurate and precise estimate of the likelihood of an accident. However, decision makers are often asked to consider activities with much less operational data, especially regarding new technologies. Estimation of likelihood in these cases may still utilize data from similar industries if care is taken not to overstate the applicability. For example, there may not be enough data on rail transportation of $\mathrm{CNG} / \mathrm{LNG}$ to accurately estimate the accident probability, but there may be sufficient accident data on rail transportation of other hazardous materials. If the relationship between the accident probability for rail transportation of CNG/LNG and the accident probability for rail transportation of other hazardous materials can be justified, then the data on other hazardous materials can be used to inform the accident probability for $\mathrm{CNG} / \mathrm{LNG}$ in lieu of CNG/LNG-specific data.

\subsection{Recommendations for Hazardous Materials, Including CNG and LNG, in Rail Transportation}

Based on the survey of a wide variety of risk methodologies and the review of applications of these methods, several methodologies adequately provide the ability to calculate the involuntary individual and societal risks for the transportation of CNG or LNG as cargo as well as fuel via rail. The specific methodology is less important than the presence of several critical elements of the risk methodology. Due to its wide use and detail, the Dutch Purple Book is used as an example to describe the critical elements of an appropriate QRA methodology to assess $\mathrm{CNG} / \mathrm{LNG}$ as cargo or fuel. The same critical elements are recommended for CNG and LNG since neither have previously been carried by rail. 
The first of these critical elements is that the societal risk is evaluated in a quantitative manner. The risk assessment methodology must be a quantitative risk assessment and should follow the basic steps outlined in Appendix A. Only a QRA methodology will allow the calculation of a societal risk. Semi-quantitative or qualitative methods which evaluate elements of the risk as subjective criteria will not yield an absolute risk value. The Dutch Purple Book, for example provides instructions that allow a societal risk curve to be calculated. It does not use subjective terms in order of magnitude values, such as high, medium, or low corresponding to once in a hundred, once in a thousand, or once in a million values for any parameters. Appropriate methodologies share this critical element, even though they may differ from the Dutch Purple Book in other ways.

The second critical element that must be included in an adequate methodology is the prescription for a full range of comprehensive scenarios that can lead to hazardous conditions. These scenarios should be bounding, meaning that worst-case loss of containment scenarios need to be included, as well as accidents involving fires and explosions. For rail transportation, this means that the bounding scenarios need to be evaluated for each discretized segment of the route. The Dutch Purple Book is again a good example of this. It provides guidance, including specific scenario definitions, as well as processes for identifying all anticipated scenarios. If some plausible scenarios are dismissed with little justification or due to the lack of data because the technology is new, these are warning signs that the methodology is not robust or detailed enough to provide FRA with a comprehensive evaluation of the risks.

The last critical element that must be included in the risk assessment methodology is that routeand segment-specific characteristics be used to calculate the total risk for the route being assessed. These characteristics include accident frequencies to assess the likelihood of hazardous material release events as well as population densities along the route to assess consequences. This will ensure that the methodology can be applied to calculate the risk for a transportation system since the incorporation of population characteristics, population densities, and varying accident rates is necessary to adequately quantify risk. If the QRA methodology makes subjective assessments of the accident frequency or population densities, the involuntary nature of the societal risk will not be assessed adequately.

Though the Dutch Purple Book is, in most respects, exemplary of an appropriate methodology for $\mathrm{CNG} / \mathrm{LNG}$ hazards, the transportation methodology includes a screening step at the beginning of the process that may not be appropriate. It provides a graded approach to the level of effort for the risk analysis based on threshold values for the type of hazardous materials being transported, the number of annual rail cars transported, population densities along a specific route section, and the track speed.

Many aspects of a proper QRA methodology are very similar between an analysis for a fixed facility and for a transportation application. Fundamentally, a QRA examining fatality risk looks at the same outcome, regardless of exactly how a fatality occurs. However, specifics of how the risk is calculated will be different for these applications due to the different nature of the hazard for each. Although the Dutch Purple Book methodology recommends quantifying societal transportation risk as a normalized value of the risk per kilometer (i.e., divide the total risk by the length of the route), it is recommended that a total societal risk curve for the entire route be used for the evaluation of $\mathrm{CNG} / \mathrm{LNG}$ on the U.S. railroad system. The reason for this is that the societal risk occurs along the entire route and the risk must consist of the sum of all the potential scenarios along the entire route. This can be accomplished by the systematic discretization of the 
route into appropriate segments based on the characteristics of the populations, track conditions, and other relevant factors along the route. The societal risk estimates for each segment are then added together to get the total route societal risk. Some jurisdictions have suggested only analyzing the single highest-risk segment of a route, or dividing the total route risk by the length of the route to get a normalized per-length risk value; the intention is to allow for direct comparisons between projects of different lengths. However, this can make the higher total risk for a long route appear to be relatively lower than the same total risk for a short route because it is normalized by length. It is recommended that total societal risk be considered directly.

Other methodologies that were surveyed and provided an adequate calculation of the risk include the Accident-Cause-Specific Risk Analysis of Rail Transport of Hazardous Materials [16] and the Center for Chemical Process Safety's Guidelines for Chemical Transportation Safety, Security, and Risk Management [18]. Although the Liu methodology does not carry the risk methodology through the calculation of the societal risk curve, the framework of calculating the risk along the route provides the key risk parameters essential for an adequate QRA methodology. 


\section{Risk Acceptance Criteria}

This section discusses risk acceptance criteria specifically, starting with a description of the basis by which criteria may be selected. Next, a summary of a literature search for applicable risk acceptance criteria examples is given and discussed with respect to the transportation of hazardous materials. Finally, recommendations on individual and societal fatality risk acceptability criteria are given and discussed.

\subsection{Selection of Risk Criteria}

The acceptability of an absolute level of risk is a subjective judgement. Given sufficient data and effort, mathematical models and equations can provide objective calculations of risk, and to compare the risk of multiple options. However, there is no mathematical model for determining if a given calculated level of risk is acceptable. This is ultimately a subjective decision by regulators, authorities having jurisdiction, or other decision-makers. Objective facts, calculations, and other quantitative factors can inform the decisionmaker as discussed below, but ultimately it is a decision about what level of risk is acceptable. This acceptability decision can be based on the benefit gained from accepting the risk, the culture of risk in a particular jurisdiction, and how the risk compares to other existing accepted risks.

Risk acceptability criteria does not have to be a single number; often a more graded approach can be beneficial. As an example, the UK Health and Safety Executive (HSE) uses a framework for the acceptability of risk based on the Royal Society's principles that was originally published in 1987 for nuclear power stations, but now applies to all health and safety risks for people at work [45]. This general concept can be applied for different types of hazards and the risk values separating each region will depend on risk acceptability.

In this concept, risk is divided into three regions:

- Unacceptable risks which are only permitted in exceptional circumstances

- Acceptable risks to be made ALARP

- Broadly acceptable risks — not normally requiring further reduction [45]

It should be noted that while this specific example is for individual risk, the ALARP concept and region also applies to societal risk by specifying an "area" of exceedance frequencies vs. number of fatalities rather than a single individual risk value.

This system has many benefits by clearly specifying the risk acceptability into three different regions. In one region, it is clearly specified under which level the risk is small enough as to be generally acceptable, in which case no further analysis or mitigation is needed. This prevents activities that do not present significant safety risk from being over-burdened by additional requirements. The top region defines which risks are unacceptable; activities that fall into this region would need to make significant changes to the design to reduce risk. This requirement can also make it clear to applicants what level of risk is completely unacceptable and therefore not worth submitting for review. Finally, this system leaves a somewhat flexible area in the middle of these two regions, in which the risk is significant enough to not be broadly acceptable, but not so high as to be totally unacceptable. This gives the decision maker options to consider the potential benefit of an activity, as well as potential prevention and mitigation measures that could be added to reduce the risk. 
The upper and negligible limits on individual risk can be informed in the following ways:

Historical risk is based on statistical analysis of activity in the past [45]. For example, individual and societal risk can be calculated based on the risk associated with a current technology. The advantage of this selection is that the criteria is readily comprehensible to the public since they have already accepted the existing risk. An example of this is comparing the risk of a refueling station for hydrogen fuel cell vehicles to a refueling station for gasoline or diesel vehicles; this compares a very similar, existing risk to a new technology. However, with emerging technologies, such as CNG/LNG-fueled locomotives or CNG/LNG cargo, this is not necessarily a directly applicable comparison given the limited data on the technology.

Background risk is based on risks from other industries or in daily life, also called comparative risk criteria [45]. The U.S. NRC risk acceptance criterion is a good example of this type of risk, in which the additional risk from a nuclear power plant is limited to 0.1 percent of the sum of prompt fatality risks to which members of the public are generally exposed (see Appendix B, Section B.2.1 ). This risk acceptance criterion does not require accidents to occur before the risk criterion can be defined, unlike historical risk. The disadvantage is that the choice of data on which to base the criteria is based only on judgement. For example, the nuclear power plant risk criteria may not be appropriate for the transportation risks, since the types of hazards and consequences are different. This type of risk criteria may be informative for hazardous material (such as $\mathrm{CNG} / \mathrm{LNG}$ ) transport, but the choice of comparison is critically important.

Reference case risk uses a representative case as a reference standard [45]. An example of this is stating that the risk for a new system should be no higher than a risk for a comparable system that has been studied and judged to be acceptable. The advantage is that the criteria can be established through detailed analysis and expert judgement on the representative case and does not require accidents to occur before risk criteria is set. The downside is that a reference must be evaluated to compare the new technology. A simple comparison of the risks is not easily completed since the new case is not necessarily comparable to the reference case. This type of risk criterion is not appropriate for $\mathrm{CNG} / \mathrm{LNG}$ as fuel or cargo since each railroad would have to generate a reference case before analyzing the risk of the added technology. It is more suited for new technologies for which the reference case has already been assessed.

Economic analysis uses cost-benefit criteria to analyze risk. This means analyzing if the probable economic benefit is greater than the probable economic penalties. This criterion is not appropriate for the assessment of $\mathrm{CNG} / \mathrm{LNG}$ because it requires assigning a value to a human life. While this is possible to do, many safety regulators and decision makers tend to assess and impose limits on risk to life and safety directly, rather than making further assumptions about the economic value of a human life. Aside from potential ethical or acceptability issues with assigning an economic value to a human life, this sort of criterion could also mean that if economic conditions significantly change, a previously approved activity could become unfavorable.

Expert judgement is a risk criterion chosen by a group of experts. It is usually driven by negotiations between different stakeholder groups and is chosen to achieve risk evaluations that conform to stakeholder expectations. Expert judgement factors into all aspects of risk calculation and acceptability but relying on expert judgement alone can appear subjective and arbitrary. As with any risk decision, expert judgement is a useful input to a decision on risk acceptability for 
hazardous materials transport. Utilizing risk criteria from a consensus of experts can be a useful basis for these criteria.

\subsection{Summary of Applicable Risk Criteria Examples}

All formal approaches to selecting a risk criterion involve subjective factors and using expert judgment to make a choice. Ideally, technical justification and consensus among regulatory agencies should also be included. Transportation of hazardous materials is a unique issue to address for societal risk, particularly because the risk aggregated over the entire length of a transport route can be far greater than the risk of a single fixed facility. The Netherlands, for example, established an explicit risk criterion for transportation risk whereas other countries aggregate transportation activities with fixed facilities. Analyzing risk acceptance criteria from other countries and applications provides a basis for understanding the level of risk accepted worldwide.

\subsubsection{Summary of Applicable Individual Risk Criteria Examples}

Some example jurisdictions give a single value of acceptable individual risk. This includes the U.S. NRC, which gives a $5 \times 10^{-7}$ limit on the fatality probability for an individual per year, based on not significantly increasing overall fatality risks to any single person relative to the general population [4]. The Inter-Departmental Coordinating Committee in Hong Kong gives a risk criteria for a hazardous installation (facility) of $10^{-5}$ per year fatality probability for an individual [46]. Both examples are for involuntary risks of those near a potentially hazardous location. The Committee for the Prevention of Disasters (Commissie Preventie van Rampen [CPR]) in the Netherlands gives an individual risk criteria fatality probability of $10^{-6}$ to an individual per year for the transportation of dangerous chemicals by road, rail, or inland waterways; it should be noted that this transportation risk criteria is equal to the individual risk criteria for stationary activities as well [47]. These examples are all for involuntary risks to those nearby to a potentially hazardous exposure, but even though they are similar, still span a range from $5 \times 10^{-7}$ to $10^{-5}$ per year.

Other example jurisdictions use the ALARP region to give a more flexible approach to risk acceptability. This includes the International Maritime Organization (IMO), which gives a maximum acceptable individual risk of $10^{-5}$ per year (i.e., fatality probability for an individual) for third parties - not crew or passengers - for new ships, and a broadly acceptable risk value of $10^{-6}$ per year [48]. It should be noted that these limits are specifically for members of the public, not crew — who may have more training on avoiding hazards — or passengers — who are voluntarily taking on risk to gain the benefit of traveling by ship.

Still, other jurisdictions do not accept risk based on fatality risk alone, but differentiate different levels of individual risk based on the type of person affected. As stated above, the IMO has different risk criteria for crew members, passengers, and members of the public - even though some of the criteria values are similar between groups [48]. The NFPA 59A, the Standard for the Production, Storage, and Handling of Liquefied Natural Gas, has an individual fatality risk criteria range of $3 \times 10^{-7}$ to $5 \times 10^{-5}$ for the fatality probability for an individual per year; below this range there are no restrictions on land usage, above the range is the criterion for the LNG facility itself, and public areas are allowed except for sensitive occupancy buildings (e.g., schools, daycares, hospitals, nursing homes, and jails) in the area in-between [8]. The Flanders region in Belgium has land-usage restrictions that specify a fatality probability criterion of $10^{-5}$ 
per year for a facility itself, $10^{-6}$ per year for residential areas, and $10^{-7}$ per year for "vulnerable locations" [49]. The Australian New South Wales Department of Planning specifies five different fatality probability criteria, ranging from $5 \times 10^{-7}$ to $5 \times 10^{-5}$ per year, which has the most stringent requirements for hospitals and schools, less stringent requirements for residential, commercial, and sporting complexes, and the least stringent criteria for industrial areas [50]. These differences arise from societal desires to avoid affecting vulnerable populations, differences in evacuation ability, as well as from a sense of what types of exposures are voluntary (i.e., a worker going to a job is voluntarily, a prisoner in a jail is not).

\subsubsection{Summary of Applicable Societal Risk Criteria Examples}

Unlike individual risk, societal risk is typically measured in ranges of limits instead of single values. While a risk acceptability for individual risk might be a single value for the fatality probability for an individual, societal risk is a range of frequencies of exceeding different numbers of fatalities. For example, the CPR in the Netherlands has a limit for fixed facilities of a frequency $(\mathrm{F})$ of $10^{-3} / \mathrm{N}^{2}$ events per year that would result in $\mathrm{N}$ or more fatalities, for greater than 10 fatalities [47]. Thus, in this type of analysis, multiple potential scenarios must be analyzed, each of which would result in a particular number of fatalities, and the likelihood (per year) would be estimated. This would generate a line or curve, and this line or curve would be compared to the line limit given. Similarly, regional authorities in Belgium have a limit of $\mathrm{F}=$ $10^{-2} / \mathrm{N}^{2}$ for values of $\mathrm{N}$ between 10 and 1,000; this analysis would not be performed for instances of less than 10 fatalities, and events that could result in more than 1,000 fatalities are not permitted [49]. Additionally, the CPR in the Netherlands has a limit of $\mathrm{F}=10^{-3} / \mathrm{N}^{2}$ events per year per kilometer of transportation distance for the transportation of dangerous goods; this analysis is only performed for the highest risk kilometer of track [46], but this may not capture the full societal risk of the entire route.

Analogous to individual risk, many examples of jurisdictions have a two-tiered risk criterion for societal risk, with an upper limit on unacceptable risk, a lower limit defining acceptable risk, and an ALARP region in between the two. This includes the Advisory Committee on Dangerous Substances in the UK, which has a risk criterion for the transport of dangerous goods for communities near roads, railways, and ports of unacceptable risks of $\mathrm{F}>10^{-1} / \mathrm{N}$ and an acceptable risk of $\mathrm{F}<10^{-4} / \mathrm{N}$ [46]. In Switzerland, the Ordinance on Protection Against Major Accidents requires assessment of risks to the public from transportation of dangerous goods (i.e., 100 meter sections of road tunnels) and fixed installations with unacceptable risk of $\mathrm{F}>10^{-3} / \mathrm{N}^{2}$ for $10 \leq \mathrm{N} \leq 10,000$ fatalities, and negligible risk of $\mathrm{F}<10^{-5} / \mathrm{N}^{2}$ for $10 \leq \mathrm{N} \leq 1,000$ fatalities [46]. The IMO [48], Hong Kong [46], and the Australian New South Wales Department of Planning [50] are other examples that have societal risk criteria with ALARP regions; see Appendix B, Section B.3 for more details. In cases with an ALARP region, risks that are below the lower criterion are acceptable and risks above the higher criterion are unacceptable. Between the two, in the ALARP region, the decision maker may decide that the risk is acceptable if the applicant sufficiently demonstrates that the cost (i.e., time, money, resources) required to reduce the risk is high compared to the associated reduction in risk. Alternatively, the decision maker may decide that such a risk is unacceptable if it is economically feasible to significantly lower the risk. The NFPA 59A also specifies societal risk acceptability criteria with an ALARP region (maximum acceptable risk of $10^{-3} / \mathrm{N}$ and negligible risk of $10^{-5} / \mathrm{N}$ ) [8]. 
One difficulty with societal risk as applied to transportation of hazardous materials is the complexity of the calculation relative to a fixed facility. For a fixed facility, the hazard is in a fixed location, and release frequencies, nearby populations, and harm to those populations can be estimated. For transportation of hazardous material, the possible location of a release can occur anywhere along the route, with varying likelihood of release, weather conditions, and population densities all along the route. This increased complexity in the calculation of societal transportation risk can also be applied to the societal risk criteria itself; some jurisdictions apply risk criteria to a single kilometer of track (Netherlands) or a single 100 meters of road tunnel (Switzerland), while others apply it per ship (IMO) or overall (UK) [46, 48]. While scaling the risk criteria with transportation length may be intuitive, this can also incentivize longer trips; if the risk criteria increases with every mile traveled, then adding miles to the trip would increase the risk limit. In all cases, the transportation route would need to be discretized in the analysis to estimate the risk, but the risk criteria should not necessarily increase with distance.

Another complication that may arise in societal risk is the limit on the maximum number of fatalities that some jurisdictions specify. Hong Kong specifies that accidents involving more than 1,000 fatalities are unacceptable [46]. In Switzerland, maximum acceptable risk is only defined up to accidents involving 1,000 fatalities, and maximum unacceptable risk is only defined up to 10,000 fatalities. By specifying that these types of events are not acceptable, the required frequency is effectively zero. A frequency of exactly zero may be difficult to prove absolutely, and so many analyses continue to define societal risk criteria that continue to slope downward, requiring more orders-of-magnitude lower frequency for high-fatality incidents.

Finally, societal risk tends not to differentiate between exposure types, whereas individual risk criteria can have different criteria for the young, old, sick, or incarcerated. This is because societal risk tends to consider the entire population, not any single individual. A proper risk assessment would consider different types of populations in the estimations of consequence; the same hazard may have a significantly greater impact on a school of children than a workplace for healthy adults, and this impact would be reflected in the societal risk F-N curve.

\subsection{Proposed Risk Acceptance Criteria and Justification}

\subsubsection{Individual Risk}

Individual risk acceptance criteria provide a check so that societal risk is not shifted to any one person. Different jurisdictions can use a range of different acceptable risk criteria; this is because risk acceptability is inherently subjective, even if it is informed by objective measures. Maximum acceptable individual risk for the examples identified in Appendix B, Section B.2 was between $1 \times 10^{-5}$ and $1 \times 10^{-7}$ for individual risk values that have a two-tier risk (ALARP region) system, and negligible risk was between $1 \times 10^{-4}$ and $1 \times 10^{-6}$ for these systems. Individual risk values with a single risk limit (i.e., no ALARP region) varied from $5 \times 10^{-5}$ to 1.5 $\mathrm{x} 10^{-8}$. The individual risk for two-tier risk systems and single risk systems is illustrated in Figure $3-1$. 


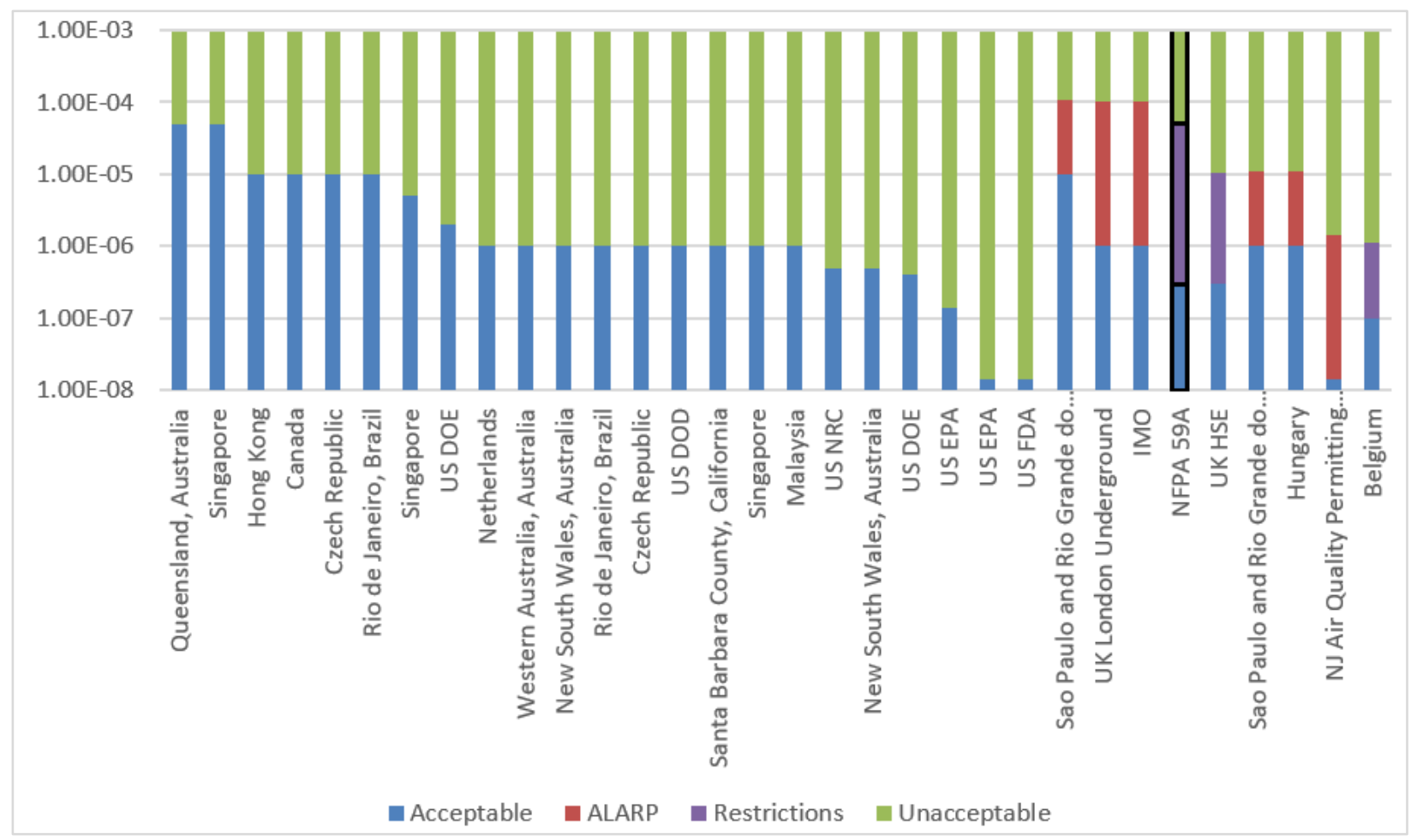

Figure 3-1. Individual risk criteria

Given the context of risk criteria used by other jurisdictions, a set of proposed risk criteria has been highlighted with a black outline in Figure 3-1; these risk criteria contain an ALARP region and generally fall in the middle of other possible risk criteria used by other jurisdictions. The proposed risk criteria are like the UK HSE, a well-respected and established body of risk analysis, and the IMO, also a well-respected body that is especially relevant for transportation applications. The proposed risk criteria are adapted from the NFPA 59A Standard [8], but with some important distinctions discussed below. The proposed risk acceptance criteria for the transport of CNG/LNG on rail is shown in Table 3-1.

Table 3-1. Proposed individual risk (IR) criteria

\begin{tabular}{ll}
\hline \hline Individual risk (per year) & Comments \\
\hline \hline Zone $1: \mathrm{IR}>5 \times 10^{-5}$ & Unacceptable \\
\hline Zone $2: 3 \times 10^{-7} \leq \mathrm{IR} \leq 5 \times 10^{-5}$ & $\begin{array}{l}\text { ALARP; applies for non-sensitive/non-vulnerable } \\
\text { populations only }\end{array}$ \\
\hline Zone 3: IR $<3 \times 10^{-7}$ & Acceptable \\
\hline
\end{tabular}

The proposed risk acceptance criteria were selected based on a "background risk" and "expert judgement." This means that the proposed risk criteria are not significantly greater than other risks that the public already accepts. This also means that the proposed risk criteria have been developed through discussions and consensus among experts. In this case, the risk criteria have been adapted from NFPA 59A, which is a consensus-based standard, reviewed by a committee of subject matter experts. NFPA is widely accepted as a global resource for minimizing risk and effects of fire. The NFPA 59A committee is responsible for safety and related aspects in the 
liquefaction of natural gas and the transport, storage, vaporization, transfer, and use of LNG. It requires individual risks to be presented in the form of contours of constant individual risk.

The NFPA 59A criteria use the same values of risk for the three zones as the recommendation, but instead of an ALARP region, the first zone is for the facility itself and the second zone is for public areas excluding sensitive establishments (e.g., schools, hospitals, nursing homes, and jails) [8]. The NFPA 59A sensitive establishment language indicates that this is specifically for institutions that may be difficult to evacuate [8]; for a fixed facility that may have an on-going leak or release, which is logical to include. However, for hazardous materials transport, a release-likely from a crash or derailment - happens quickly, making evacuation less relevant. If either population would be exposed to the same hazard regardless of evacuation time, then they have the same vulnerability.

Instead of the NFPA 59A approach for sensitive/vulnerable establishments, the recommendation is that risk to non-sensitive/non-vulnerable populations is not evaluated to a separate criterion; it is evaluated to the lower criterion for sensitive/vulnerable populations and is only considered acceptable at higher values at the discretion of the regulator. Thus, according to the recommendation, the risk to the public must be lower to be considered clearly acceptable than it would be according to NFPA 59A, and the risk estimate for hospitals, jails, etc. must be as low as required by NFPA 59A to be considered clearly acceptable. This is consistent with the notion that most hazards associated with $\mathrm{CNG} / \mathrm{LNG}$ transportation occur too quickly for evacuation to affect risk so the public is comparable to the vulnerable population considered in NFPA 59A.

The proposed criteria use the idea that the risk in-between the acceptable and unacceptable values should be ALARP. In other words, NFPA 59A considers a higher risk acceptable if it does not pertain to a vulnerable population, whereas the recommendation requires further justification in addition to the population type (non-sensitive/non-vulnerable) before the higher risk can be considered acceptable at the decision-maker's discretion. This requires a lower risk for automatic acceptability for the general population, but still gives the decision-maker some flexibility, and requires the same risk for automatic acceptability for sensitive/vulnerable populations as NFPA59 A. This use of ALARP is consistent with other transportation risk acceptance criteria values, such as the London Underground, UK HSE, and IMO [46, 48]. By designating an ALARP region, it allows for flexibility in the decision-making process where acceptable mitigations or best practices can be implemented to reduce the risk. For example, prevention and mitigation measures could include decreasing the speed through densely populated areas, reducing the amount of CNG/LNG being transported, or changing the type of container used for $\mathrm{CNG} / \mathrm{LNG}$ transportation. This gives regulators flexibility to address local concerns or issues specific to a particular route or project.

\subsubsection{Societal Risk}

Societal risk criteria attempt to ensure that the rate of accidents and associated hazardous effects that could affect people in a community are minimized to the extent possible. Examples of societal risk criteria are illustrated in Figure 3-2. The slope of the curve reflects the organization's degree of risk aversion. A slope of -1 on a log-log scale is typically regarded as being "risk neutral," according to the Guidelines for Developing Quantitative Safety Risk Criteria, so that incidents with more fatalities should be less likely, although some countries choose to reflect their higher risk aversion by using a higher magnitude slope [27]. 


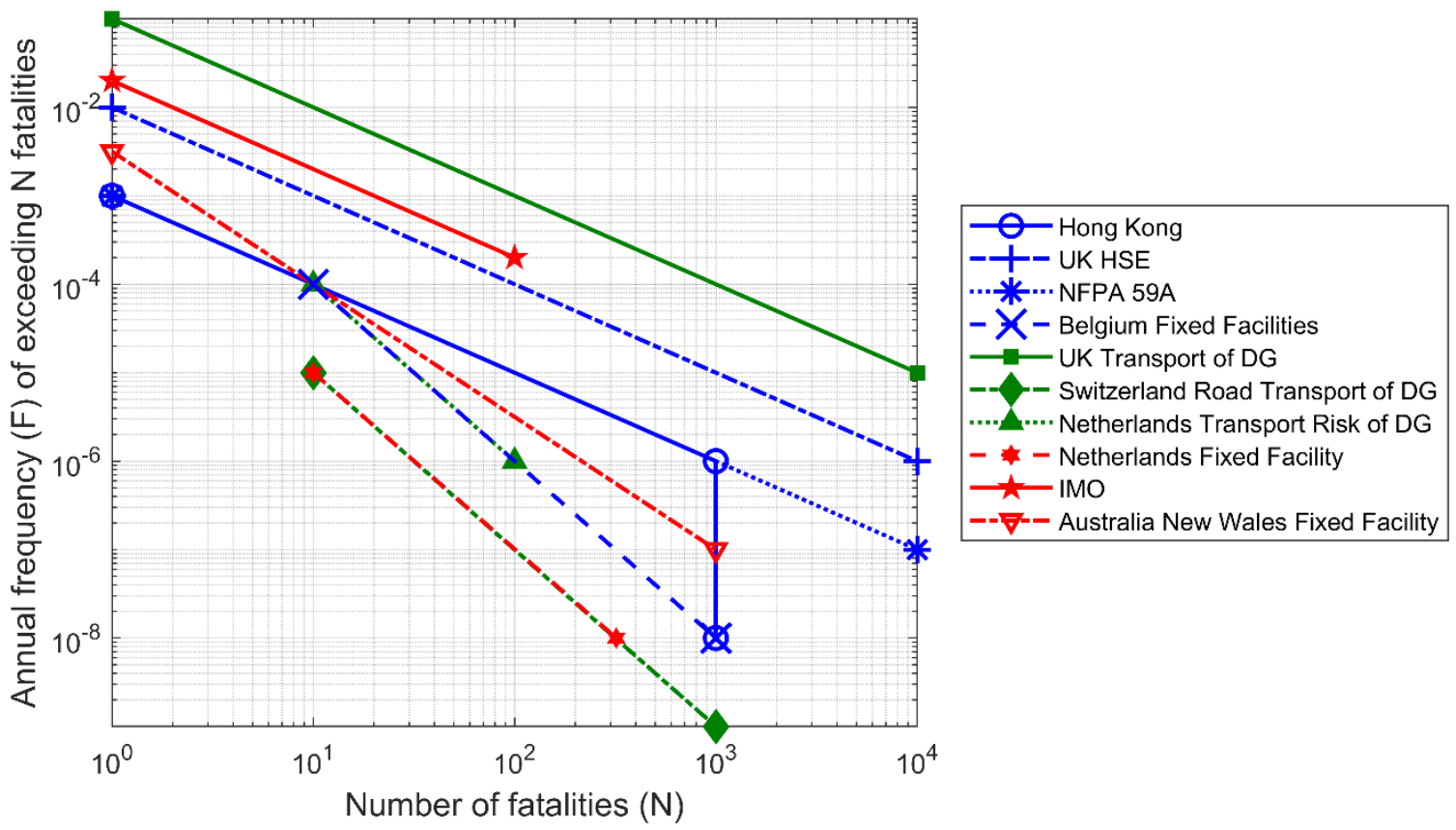

Figure 3-2. Summary of maximum acceptable societal risk criteria

NFPA 59A societal fatality risk is in the middle range of risk criteria, is not on either extreme end of societal risk criteria, and has a -1 slope. These risk criteria are similar, but below that of the UK HSE and the IMO. In addition, the NFPA 59A societal risk values include an area where risk must be demonstrated to be ALARP. The proposed societal fatality risk acceptance criteria for CNG/LNG transport on rail is shown in Figure 3-3. These criteria are a limit on unacceptable risk of $\mathrm{F}>10^{-3} / \mathrm{N}$, a limit of $\mathrm{F}<10^{-5} / \mathrm{N}$ for acceptable risk, and a region in-between the two for which the applicant must justify that the risk is ALARP (i.e., the risk is as close to the acceptability criterion as is economically feasible and appropriate mitigations can be instituted) and acceptance may or may not be granted. 


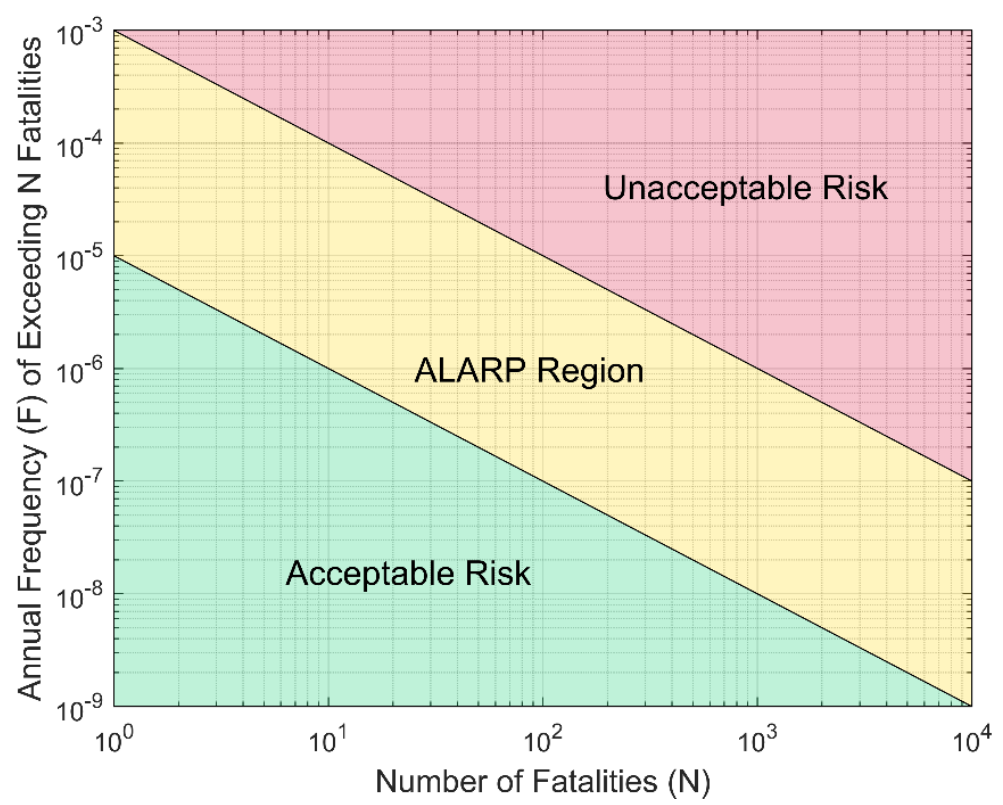

Figure 3-3. NFPA 59A acceptability regions of societal fatality risk in the F-N domain [8]

An important distinction that must be made is that these proposed risk criteria should be applied to the entire $\mathrm{CNG} / \mathrm{LNG}$ transport route being considered; these risk criteria are not to be applied to only a specified subset length of the route, nor are they to be applied to a normalized length of track (i.e., per kilometer or per mile of track). The proposed risk criteria should be applied to the sum of risk over the entire $\mathrm{CNG} / \mathrm{LNG}$ route, from the point at which $\mathrm{CNG} / \mathrm{LNG}$ is loaded onto the train to the point at which it is off-loaded. Since train derailments or crashes typically have a frequency on a per-mile basis, longer routes will have a higher annual likelihood of CNG/LNG release compared to shorter length routes, and thus a higher risk. Shorter routes may be generally more likely to meet the acceptable risk criteria. The application of the acceptability criteria above for the total shipment route risk is intentional, as this ensures the risk criteria are tied to the overall risk to the society - that is potentially exposed to the harm from hazmat releases from train accidents - and not normalized on a per-unit length basis. 


\section{Conclusion}

This report provides a recommendation and justification for FRA to adopt a quantitative risk assessment methodology for the transport of CNG/LNG on rail. The recommendation is general and can be applied to other hazardous materials if those materials present similar hazards and the time scale over which harm would be caused by a potential accident is comparable. The Dutch Purple Book was used as an example methodology because it is widely accepted across many industries and has been implemented extensively in countries that have risk-based regulations, such as the UK and Netherlands. The methodology captures the unique aspects of hazardous material transportation on rail in a comprehensive way. Also, the methodology contains detailed instructions on calculating individual and societal risk in units of individual fatality probabilities and annual fatality rates which is how the proposed criteria are presented. Though the Dutch Purple Book is not the only acceptable methodology, it is exemplary of the essential components all acceptable methodologies should include.

The assessment of safety risk is a general analysis; a fatality is a fatality, regardless if it occurred from a CNG/LNG leak from a fixed facility or from a derailed train. As such, the application of risk methodologies and criteria can have many identical aspects between fixed facility risk and transportation risk. However, the quantification and assessment of these risks must take application-specific features into account. A fixed facility is geographically fixed, making the physical location of $\mathrm{CNG} / \mathrm{LNG}$ releases relatively easy to locate to a specific area, and the surrounding area is fixed and knowable. Hazardous material transportation, on the other hand, has a hazard that moves through space and time over a long route, making the specific release location and likelihood somewhat less intuitive to predict. Potential release scenarios must be considered along the entire length of the route, considering train speed, track conditions, weather, and nearby population density along the track. All these factors will affect the calculation of risk, and so must be considered carefully.

A survey of risk acceptance criteria was conducted, focusing on transportation risk applicable to hazardous materials transport, for both individual and societal fatality risk. Although no risk acceptance criteria were found that were directly applicable to the transport of $\mathrm{CNG} / \mathrm{LNG}$ over rail, the survey illustrated the type of criteria needed to make systematic and consistent evaluations. Individual risk acceptance criteria were recommended so that annual individual fatality probabilities are acceptable if less than $3 \times 10^{-7}$, subject to further scrutiny when as low as reasonably practicable (ALARP) between $3 \times 10^{-7}$ and $5 \times 10^{-5}$ for non-sensitive/nonvulnerable populations, and unacceptable when greater than $5 \times 10^{-5}$. These criteria are adapted from NFPA 59A criteria, which is the standard for siting LNG fixed facilities. The individual risk limit values are the same as NFPA 59A, but are applied instead to only allow higher risk for non-sensitive/non-vulnerable populations at the regulators discretion. This difference between the recommendation and NFPA 59A was made because the specific hazards associated with $\mathrm{CNG} / \mathrm{LNG}$ transportation progress quickly, which reduces the benefit gained by non-vulnerable populations due to evacuation ability. Populations that would not be considered vulnerable in a fixed facility analysis may be considered vulnerable with respect to hazardous material transportation, so the lower NFPA 59A criterion is the only criterion below which the recommendation defines clearly acceptable risk.

Societal risk values do not apply to any individual, but to expose the whole population, while the individual risk limit ensures that societal risk is not simply shifted to a small number of 
vulnerable individuals. As an example, consider a crude oil pipeline. The pipeline may cover a large distance and avoid metropolitan areas. Because of this, the societal risk from a pipeline rupture may be low. But if the pipeline is directed near a small community, the risk for those individuals may be unacceptably high. If both societal and individual risk criteria must be met, this scenario would be unacceptable, whereas it might be deemed acceptable if only societal risk is considered.

Societal risk limits are typically expressed as a limit on the frequency per year (F) with which accidents can occur that would result in the consequences exceeding a given number of fatalities (N). This F-N criterion can be plotted as a line on a plot, and a quantitative risk assessment can generate a curve on the same plot for a particular application, facility, activity, or transportation route for comparison. The recommended societal risk criteria values are the same as NFPA 59A societal risk values for fatalities, applied to the entire $\mathrm{CNG} / \mathrm{LNG}$ route. These values are a limit on unacceptable risk of $\mathrm{F}>10^{-3} / \mathrm{N}$, a limit of $\mathrm{F}<10^{-5} / \mathrm{N}$ for acceptable risk, and a region in between the two for which risks must be demonstrated to be ALARP and approval is not guaranteed. Analogous to being applied to a single fixed facility (i.e., NFPA 59A itself), these societal criteria should be applied to an entire route of $\mathrm{CNG} / \mathrm{LNG}$ transport over rail. Thus, the criteria are not applied only to a certain length of track or normalized over the total length of the route, which could allow for acceptance of a higher fatality frequency for a longer route than for a shorter route. The sum of risk over the entire route must be analyzed and compared to the societal risk criteria to fully capture the total risk. 


\section{References}

1. Kaplan, S., Garrick, B. J., and Apostolakis, G., Advances in Quantitative Risk AssessmentThe Maturing of a Discipline. IEEE Transactions on Nuclear Science, 1981. NS-28(1).

2. CCPS Process Safety Glossary. [cited 2019 March 14].

3. Starr, C., Social Benefit versus Technological Risk. Science, 1969. 165(3899): pp. 12321238.

4. Safety Goals for Nuclear Power Plant Operation, U.S. Nuclear Regulatory Commission NUREG-0880, 1983.

5. Diamantidis, D., Background Documents on Risk Assessment in Engineering: Risk Acceptance Criteria, Joint Committee of Structural Safety, 2008.

6. Reducing risks, protecting people: HSE's decision-making process. 2001, HSE Books: Health \& Safety Executive.

7. Uijt de Haag, P. A. M. and Ale, B. J. M., Guidelines for Quantitative Risk Assessment: Purple Book. Publication Series on Dangerous Substances (PGS 3). 2005: Ministerie van Volkshuisvesting en Ruimtelijke Ordening (VROM).

8. NFPA 59A, Standard for the Production, Storage, and Handling of Liquefied Natural Gas (LNG). 2019, National Fire Protection Association.

9. Kaneko, F., Methods for probabilistic safety assessments of ships. Journal of Maritime Science and Technology, 2002, 7: pp. 1-16.

10. Ozbas, B., Safety Risk Analysis of Maritime Transportation: Review of the Literature. Transportation Research Record: Journal of the Transportation Research Board, 2013, 2326(1): pp. 32-38.

11. Kawprasert, A. and Barkan, C. P. L., Communication and Interpretation of Results of Route Risk Analyses of Hazardous Materials Transportation by Railroad. Transportation Research Record: Journal of the Transportation Research Board, 2009, 2097(1): pp. 125-135.

12. Liu, X., Analysis of Collision Risk for Freight Trains in the United States. Transportation Research Record: Journal of the Transportation Research Board, 2018, 2546(1): pp. 121128.

13. Liu, X., Saat, M. R., and Barkan, C. P. L., Safety Effectiveness of Integrated Risk Reduction Strategies for Rail Transport of Hazardous Materials. Transportation Research Record: Journal of the Transportation Research Board, 2013, 2374(1): pp. 102-110.

14. Liu, X., Saat, M. R., and Barkan, C., Integrated risk reduction framework to improve railway hazardous materials transportation safety. Journal of Hazardous Materials, 2013, 260: pp. 131-140.

15. Liu, X., Saat, M. R., and Barkan, C., Probability analysis of multiple-tank-car release incidents in railwayhazardous materials transportation. Journal of Hazardous Materials, 2014, 276: pp. 442-451. 
16. Liu, X., Turla, T., and Zhang, Z., Accident-Cause-Specific Risk Analysis of Rail Transport of Hazardous Materials. Transportation Research Record: Journal of the Transportation Research Board, 2018, 2672(10): pp. 176-187.

17. Saat, M. R., et al., Environmental risk analysis of hazardous material rail transportation. Journal of Hazardous Materials, 2014, 264: pp. 560-569.

18. Center for Chemical Process Safety, Guidelines for Chemical Transportation Safety, Security, and Risk Management. 2005: John Wiley \& Sons, Inc.

19. Bendixen, L., Freeman, R., and Hendershot, D., Using the CCPS Guidelines for Chemical Transportation Risk Analysis. Process Safety Progress, 1997, 16(1): pp. 32-36.

20. Claros, B., Sun, C., and Edara, P., Enhancing Safety Risk Manageemnt with Quanititative Measures. Transportation Research Record: Journal of the Transportation Research Board, 2017, 2603(1): pp. 1-12.

21. DOE Transportation Risk Assessment Working Group Technical Subcommittee, A Resource Handbook on DOE Transportation Risk Assessment. Vol. DOE/EM/NTB/HB-01. 2002, Albuquerque, NM: National Transportation Program.

22. Hwang, S. T., et al., Risk Assessment for National Transportation of Selected Hazardous Materials. Transportation Research Record: Journal of the Transportation Research Board, 2001, 1763(1): pp. 114-124.

23. Introduction to Risk Management, National Heavy Vehicle Regulator: Australia. pp. 1-24 2017.

24. Stamatelatos, M., NASA Activities in Risk Assessment, in NASA Project Management Conference. 2004: NASA Headquarters.

25. NASA, NASA Risk Management Handbook. Vol. NASA/SP-2011-3422, Version 1.0. 2011, Washington, DC: Office of Safety and Mission Assurance.

26. Weiner, R., et al., RADTRAN 6 Technical Manual SAND2014-0780, Sandia National Laboratories: Albuquerque, NM, 2014.

27. Guidelines for Developing Quantitative Safety Risk Criteria. 2009: American Institute of Chemical Engineers: Center for Chemical Process Safety.

28. Beroggi, G., et al., Risk Assessments in the Netherlands, TU Delft, 1997.

29. Risk Assessment and Risk Management, Health and Safety Executive: Buxton, UK. pp. 1-25, 2005.

30. Review of Railway Safety's Safety Risk Model, HSE, Health and Safety Laboratory: Buxton, UK, 2012.

31. Rhomberg, L., A Survey of Methods for Chemical Health Risk Assessment Among Federal Regulatory Agencies, National Commission on Risk Assessment and Risk Management: Boston, MA. pp. 1-172, 1995.

32. Storage and Handling of Dangerous Goods: Code of Practice. 2005, Government of New South Wales, Australia: Gosford, New South Wales, Australia, pp. 1-192. 
33. Managing Risks of Hazardous Chemicals in the Workplace: Code of Practice. 2012, Safe Work: Australia.

34. Dangerous Goods Safety Guidance Note: Generating the supporting documentation for an MHF safety report. 2009, Government of Western Australia, Department of Mines and Petroleum, pp. 1-29.

35. Swedish National Risk Assessment Swedish Civil Contingencies Agency (MSB), Swedish Civil Contingencies Agency, pp. 1-64 2012.

36. National Risk Analysis, DSB, Norwegian Directorate for Civil Protection, 2014.

37. National Risk Assessment 2015, Ministry of the Interior: Finland, 2015.

38. Gaseous Hydrogen Fuelling Stations - Part 1: General Requirements, in ISO 19880-1, ISO, Editor. 2018, International Standards Organization: Geneva, pp. 1-189.

39. Guidelines for Formal Safety Assessment (FSA) for Use in the IMO Rule-Making Process, International Maritime Organization: London, p. Annex E, 2002.

40. Balmat, J.-F., et al., Maritime Risk Assessment (MARISA), a fuzzy approach to define an individual ship risk factor. Ocean Engineering, 2009. 36(15-16): pp. 1278-1286.

41. Amendments to the Guidelines for Formal Safety Assessment (FSA) for Use in the IMO RuleMaking Process, International Maritime Organization, London, p. Annex E, 2006.

42. A Proposed Risk Management Regulatory Framework, Nuclear Regulatory Commission Risk Management Task Force NUREG_2150, pp. 1-318, 2012.

43. Reexamination of Spent Fuel Shipment Risk Estimates, Nuclear Regulatory Comission NUREG/CR-6672: Washington, DC, pp. 1-315 2000.

44. Probabilistic Risk Criteria and Safety Goals, Nuclear Energy Agency, Committee on the Safety of Nuclear Installations NEA/CSNI/R(2019)16, 2009.

45. Harmonised Risk Acceptance Criteria for Transport of Dangerous Goods, Det Norske Veritas (DNV) PP070679/4, Rev. 2: London, 2014.

46. Risk Acceptance Criteria and Risk Based Damage Stability Final Report, part 1: Risk Acceptance Criteria, European Maritime Safety Agency 2015-0165, Rev. 1 DNG GL2/24/2015, 2013.

47. Bottelberghs, P. H., Risk analysis and safety policy developments in the Netherlands. Journal of Hazardous Materials, 2000, 71(1): pp. 59 - 84.

48. Revised Guidelines for Formal Safety Assessment (FSA) for Use in the IMO Rule-Making Process. 2018, International Maritime Organization.

49. Guidance on Land-Use Planning, the Siting of Hazardous Activities and related Safety Aspects, United Nations Economic Commission for Europe, 2017.

50. Risk Criteria for Land Use Safety Planning State of South Wales through the Department of Planning: Sydney, Australia, 2011.

51. Kaplan, S. and Garrick, B. J., On the quantitative definition of risk. Risk Analysis, 1981. 1(1): pp. 11-27. 
52. Guidance on the Treatment of Uncertainties Associated with PRAs in Risk-Informed Decisionmaking, NUREG-1855, Revision 1, 2017.

53. Offshore QRA-Safeti Offshore. [cited March 13, 2019].

54. Shepherd Software. [cited March 13, 2019].

55. Hong Kong Planning Standards and Guidelines, Chapter 12 : Miscellaneous Planning Standards and Guidelines, Planning Department, 2011, The Government of Hong Kong Special Administrative Region.

56. Technical Memorandum on Environmental Impact Assessment Process, Annex 4 : Criteria for Evaluating Air Quality Impact and Hazard to Life, Environmental Protection Department, 1997, The Government of Hong Kong Special Administrative Region.

57. Liquefied Natural Gas (LNG) Receiving Terminal and Associated Facilities: Quantitative Risk Assessment, EIA Study Brief ESB-126/2005, 2006.

58. Commission Implementing Regulation (EU) on the common safety method for risk evaluation and assessment and repealing Regulation (EC) No 352/2009, 2013, Official Journal of the European Union.

59. Commission Implementing Regulation (EU) amending Implementing Regulation (EU) No 402/2013 on the common safety method for risk evaluation and assessment No 2015/1136, 2015, Official Journal of the European Union.

60. HSE's Land Use Planning Methodology, Health and Safety Executive. 


\section{Appendix A. QRA Method Overview}

The applicability of risk acceptance criteria is closely related to the specifics of the method by which the risk is calculated. Therefore, this section provides additional detail and commentary on a quantitative risk assessment process and reviews current tools that can be used to perform a quantitative risk assessment.

\section{A.1 Quantitative Risk Assessment}

The basic form of a quantitative risk assessment (QRA) is provided in this section, with explanation of each step to show the common form of all QRA processes, regardless of whether it is being used to evaluate the safety of a fixed facility or a mobile system. All the QRA methodologies surveyed follow these basic steps.

At the highest level, QRA is the process of quantifying the risks associated with an activity. The result of a QRA is an estimate of risk in a context-specific unit that can be used by decisionmakers to determine whether the benefits of the activity are worth the quantified risk, make riskbased regulatory decisions, and to prioritize risk mitigation strategies. Most people engage with a qualitative notion of risk assessment when making day-to-day decisions, like picking a route to take home during rush hour or buying movie tickets ahead of time. There is a non-zero risk of getting stuck in traffic or showing up to a sold-out show, and we use our prior experiences, familiarity, and intuition to decide whether that risk is low enough to take or not. QRA formalizes this familiar notion of risk assessment into a structured process that removes subjective judgements to the extent possible.

The classical definition of risk assessment, as presented in Kaplan and Garrick [51], is the process used to answer the following questions:

1. What can go wrong?

2. What is the likelihood it will go wrong?

3. If it does go wrong, what are the consequences?

A fourth question is commonly added to this list, whether explicitly or implicitly [1]:

4. How confident are we in our answers to the first three questions?

This last question acknowledges that, while QRA attempts to provide a complete and objective quantification of risk, there are always uncertainties and assumptions in the assessment that must be acknowledged as part of that presentation of risk. Figure A-1 depicts the overall QRA process used to perform risk assessment.

\section{What can go wrong?}

The first step in Figure A-1 is to define the scope of the assessment. This step sets limits on what is included in the consideration of "What can go wrong?" For example, if the consequence of concern is fatalities, the scope of the analysis would exclude consideration of events that cannot lead to fatalities. This step is essential for defining the problem, so the final assessment provides the information that decision-makers need. 
Once the scope is defined, the plausible scenarios within that scope are identified. A scenario is a sequence of events that, if they occurred, could lead to the undesired consequence. This step in the QRA process is an important point at which to consider uncertainty. Depending on the complexity of the system or process being analyzed in the QRA, it may not be obvious if the analyst(s) failed to identify a plausible scenario. A conscious effort should be made in the analysis to establish that "What can go wrong?" is adequately answered with the scenario set.

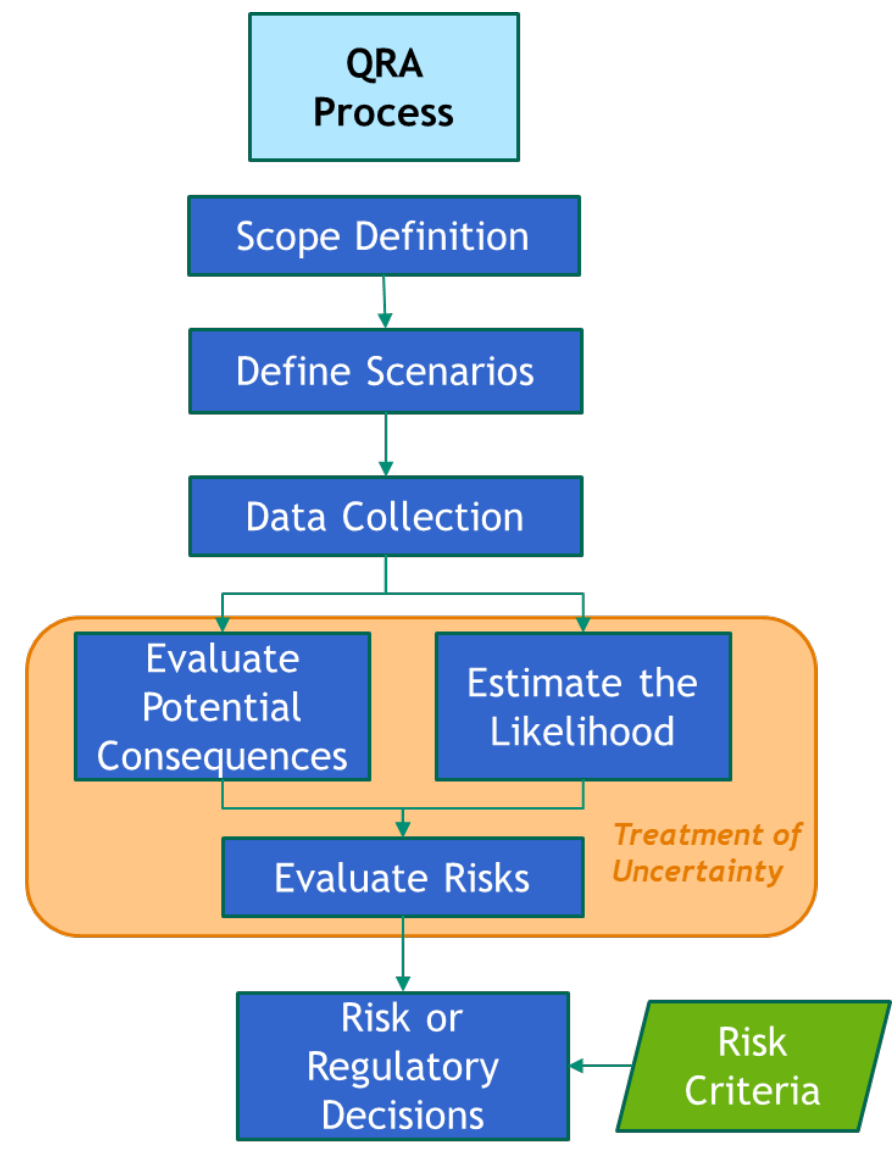

Figure A-1. Graphical representation of the QRA process

\section{What is the likelihood it will go wrong?}

The remaining steps in the QRA analysis are applied to the identified scenarios to determine the likelihood of occurrence of each scenario and the magnitude of the resulting consequences. Data collection broadly refers to many of the methods that can be applied to establish the technical basis for the likelihood and consequences. This may involve modeling complex systems (i.e., nuclear reactors, hazardous materials dispersion, climate conditions, etc.), performing experiments, reviewing literature, and surveying experts. The methods employed depend on the complexity of the scenario and the current state-of-knowledge. All the data collected in this process is used to estimate the frequency of the events (generally on an annualized basis for events of concern to safety evaluations) that define the scenarios leading to consequence. This establishes "What is the likelihood it will go wrong?" 


\section{If it does go wrong, what are the consequences?}

Collected data is applied to estimate the consequences for each scenario. Depending on the analysis, these consequences may be human losses (e.g., injuries, deaths, illnesses, etc.) or monetary/economic losses. Consequence is an essential component of risk because it establishes the potential cost of the ultimate decision. Likelihood and consequence together define the risk estimate from the QRA, which is commonly presented as individual risk, societal risk, or industry specific risk (e.g., radiation exposure). Considerable judgment may be involved in decision-making based on risk results. One aid to assist in such decision making is a quantitative measure of the acceptable risk values.

\section{How confident are we?}

Use of the risk estimate to make decisions about accepting risk requires that decision-makers have confidence in the fidelity of the estimate. Each step in the process introduces uncertainty and an opportunity for the analyst to unconsciously bias the estimate away from the actual risk. If the QRA does not identify a scenario that in reality increases the risk, then the risk estimate may convince decision-makers to accept a risk that is higher than they believe. Similarly, the data collection process leads to estimates for the likelihood and consequences of scenarios. Judgements made during this process, such as using inaccurate models, faulty data, inappropriate assumptions, non-converged solutions, etc. can bias both components of risk, potentially misleading decision-makers regarding the true risk.

This highlights the importance of the fourth question commonly added to the Kaplan and Garrick risk triplet: "How confident are we in our identification of what can go wrong, its likelihood, and the potential consequences?" The answer to this question can be addressed in multiple ways. For example, analysts may quantify the uncertainty throughout the analysis and produce uncertainty bounds on the final risk estimate. For assumptions, it is common to use sensitivity studies to demonstrate the effect on the risk estimate of key assumptions, establishing whether those assumptions need further justification or not [52].

\section{A.1.1 Scenarios and Scope}

The scope of a QRA determines the set of scenarios included in the analysis. This section further examines methods used to identify and develop these scenarios to support quantification of risk.

QRA is often used with complex systems in which the answer to the question "What can go wrong?" is not straightforward. The progression of a scenario from an initiating event to a consequence can be affected by physics, human actions, unpredictable conditions, random effects, and interactions between different system components. At each stage of a scenario, any number of different events may occur, or interact, and change the course of the scenario such that it results in greater consequences, or reduced consequences. Adequately characterizing the sequence of events in a scenario and the resulting consequences requires a balance between in scenario complexity. This process can be made more tractable by using event sequence diagrams to develop scenarios and reducing the number of scenarios to a representative or bounding set.

Event sequence diagrams, or event trees, are tools used to map out the sequence of events that occur after an initiating event and contribute to the magnitude of consequence. The diagram begins with the initiating event. At each subsequent step, the diagram divides the progression into alternate scenarios based on the success or failure of events or conditions. As an example, an 
initiating event may be a train derailment. The next step in the diagram may be whether the derailment occurs in a populated area or not. Scenarios for which the derailment occurred in a populated area would then be developed further in the diagram, whereas scenarios for which the derailment occurred away from a populated area may terminate since they could not lead to fatalities. Event sequence diagrams provide an additional benefit if they are implemented in software that can perform calculations for the scenarios. Each event in the tree can be assigned a probability that allows the analyst to estimate the likelihood of each individual scenario characterized within the diagram.

QRAs can also be made more tractable by reducing the total number of scenarios to a representative set with comparable consequences. As an example, one scenario may initiate with a broken rail. Another scenario may initiate with foreign object impeding the track. If both scenarios ultimately lead to derailment with identical accident progressions after these initiating events, then the initiating event frequencies (i.e., broken rail, foreign object impediment) may be added and the scenarios combined for the analysis. This type of logical reduction allows the QRA to characterize the full range of possible consequences, without characterizing in detail the full range of possible scenarios.

\section{A.1.2 Data Collection}

For all types of risk scenarios, for both stationary and mobile systems, a specific risk equation is developed during the QRA process. This risk equations consists of any number of factors relevant to the specific application of which the quantified risk will be a function. For example, to characterize the risk of a scenario involving a fire at a chemical factory, factors such as the frequency of flammable material leaks or releases from different types of equipment, the distance to ignition sources, and the extent of flammable concentration are considered. Different scenarios within a given facility or transportation systems have different lists of risk factors. To calculate the risk value, data for each variable in the risk equation need to be collected. One method of addressing hazardous material transportation risk [22] considers factors like industry data, databases, shipment quantity and container information shipment frequency, as well as analysis components like national commodity flow analysis and routing models.

Across many of the methodologies surveyed, the availability of the required data is a critical aspect of the risk analysis process. If the data is known and readily available, uncertainty treatment in later tasks of the methodology is more easily undertaken. For example, for rail industry QRA, detailed train accident data has been collected and published for many years. This allows initiating event frequency data to be incorporated into the QRA. If the required data is not known but easily collected, many methodologies prescribe that a data collection effort be undertaken to generate relevant data for the analysis. In many cases however, some factors of the risk equation do not have data available or are not easily collected. The methodologies surveyed had a range of ways of dealing with addressing this problem. In some methods, assumptions are made to allow factors to be inconsequential to the risk calculation and thus, ignored. In other methods, semi-relevant data from other similar industries or applications are used in place of unavailable data. This is especially the case for new emerging technologies, such as hydrogen refueling stations, where no failure or leak data exists for the types of equipment used in these systems. In this case, the hydrogen industry used leak and release data from the oil and gas industries for component leaks rates and utilized a statistical method to update the data with hydrogen-specific data where it was available. 
Where no relevant data is available or can be adapted or collected, some methodologies make assumptions directly about the data utilizing expert opinion to help describe an uncertain distribution for the data. The uncertainty around this data tends to have the largest uncertainty when this is considered.

A list of common data required was compiled in Table A-1 from the survey of risk methodologies pertaining to transportation of hazardous materials.

Table A-1. Compiled list of data requirements for hazardous materials transport risk methodologies

\begin{tabular}{|l|l|l|l|}
\hline \multicolumn{1}{|c|}{ Commodity Data } & \multicolumn{1}{c|}{ Route Data } & \multicolumn{1}{c|}{ Carrier Data } & \multicolumn{1}{c|}{ Rail Specific Data } \\
\hline Quality of hazardous materials per shipment & Traffic density, speed & Mode of transport & Train length \\
Annual hazardous material shipment & Route characteristics & Age of carrier & Point of derailment \\
Package hazardous material capacity & Route length & Carrier condition & Hazardous materials placement in train \\
Size of release & Route conditions & Carrier history & Human factors \\
Package design & Time of day & Human factors & Accident cause \\
Chemical-specific characteristics & Weather/wind & Accident cause & Number of yards visited \\
Chemical-specific hazards & Visibility & & \\
Package pressure and temperature & Population density & & \\
\hline
\end{tabular}

Risk is classically defined using the elements of likelihood and consequence. The consequence component, which is the third question of the Kaplan and Garrick characterizations of risk, relates to the effect of an undesirable event [51]. The consequence component of risk may require complex models to estimate. Demonstrating the quality of those models is an essential component of the consequence evaluation. Consequences because of a rail accident involving LNG, for example, depend on the volume being transported, the type of accident, where the containers are located in the train consist, how much force is exerted on them, crashworthiness of the containers, available ignition sources and their location along the track, etc. If a consequence model incorrectly handles any of these factors or their complex interactions, the risk estimate produced by the model may be wrong or misleading. Similarly, consequence evaluations often include assumptions, data, conservatisms, and expert judgements, all of which should be justified to support the consequence evaluation component of a QRA.

Where data is unavailable or insufficient, complex modeling and/or expert judgement can be used. Due to uncertainties in complex models or limitations in expert knowledge, estimation of likelihood using these tools often includes significant conservatisms. Uncertainties may be characterized using uncertainty distributions rather than, or in combination with, conservative assumptions.

Depending on the complexity of the system being modeled and the availability of data, likelihood may be estimated directly, or it may be estimated as a combination of likelihoods of events. For airplane travel, data can be used directly to calculate an annual probability because the data is representative precisely of the scenario of interest. For systems without directlyapplicable data, the overall likelihood may be derived using sequences of events. For example, consider transportation of a hazardous material where the likelihood of interest is the probability of an accident resulting in an explosion. Unless accidents are a common event, sufficient 
directly-applicable data for this probability does not exist. However, the probability can be characterized as the product of conditional probabilities:

\section{P(Accident) $x$ P(Release|Accident) $x$ P(Ignition|Release).}

If transportation of the hazardous material is a common occurrence in this example, there may be sufficient operational data to estimate the probability that an accident will occur. There may be models that can be used to estimate the probability of a release given a range of impact insults. And finally, there may be experimental evidence that can be used to estimate the probability of ignition given release. In this example, the likelihood of the scenario can be estimated, with uncertainty, because a tool (i.e., data/experiments/modeling/expert judgement) is available to estimate the likelihood of each event that defines the scenario, also with uncertainty.

As with consequence evaluation, likelihood evaluation can involve complex modeling, uncertainties, expert judgements, and conservatisms. Components that contribute to the quality of the evaluation, like the validity of models, applicability of data, sufficiency of uncertainty characterizations etc., build confidence in the likelihood estimate.

Risk calculated for different applications or industries is fundamentally the same concept. A fatality is a fatality, regardless of how it occurs. From that standpoint, different risk assessment methods, data, and criteria can be applied between industries. However, different types of activities or applications will have different ways of calculating hazards and therefore the safety risk.

\section{A.2 Uncertainty}

Though the equation for risk is itself straightforward, estimation of the likelihood and consequence components is non-trivial and can include significant uncertainty. Uncertainty in these estimates relates to the fourth question added to the Kaplan and Garrick risk definition (i.e., how much confidence is there in our answers to what can happen, how likely it is, and what are the consequences) [1]. There can be many sources of uncertainty both in the likelihood and the consequence estimates due to inherent randomness (aleatory), state-of-knowledge uncertainty (epistemic), or a combination of the two. Some QRA methodologies define requirements or guidelines for the inclusion of these uncertainties in the risk calculation, including those for LNG fixed facilities, maritime risk, space launches, and nuclear reactors.

Uncertainties can be included as intervals around estimated values in the likelihood and consequence calculations or as distributions around these values. These uncertainties may be derived using a variety of methods, including distributional assumptions (e.g., a value is normally distributed), expert elicitation, Bayesian methods, etc. Propagating the uncertainties through the likelihood and consequence calculations gives a final estimate of risk with uncertainty, which can be communicated as a best estimate with uncertainty bounds, an interval, or a distribution.

Model uncertainty presents an additional challenge for QRAs. If the data collection portion of the QRA includes physical models or simulation, then the risk estimates depend on the validity of those models. Model uncertainty can arise from the model form, model parameters, numerical error, or implementation errors. Some of this uncertainty can be addressed qualitatively by assessing the limitations of applied models and the potential effects of those limitations on the risk estimate. Robust quality assurance methods and model validation can also be used to build 
confidence in models. Model choice can be addressed quantitatively using sensitivity studies with multiple alternate models. In the absence of a 'best' model, QRAs may also employ models that are demonstrated to be conservative.

\section{A.3 Risk Assessment Tool}

Several software platforms are commercially available that assist in the implementation of the methodology and provide guidance and assistance in interpretation of the methodology tasks, initially developed for the oil and gas industry. It should be noted that the Dutch Purple Book references a software program for the rail route specific population characteristics and accident rates that is not available, Inter Province Committee for Risk Calculation Methodology (IPORBM).

\section{A.3.1 Software for the Assessment of Flammable, Explosive and Toxic Impact (Safeti)}

Safeti is a commercial software package developed by DNV GL which carries out QRA of onshore process, chemical, and petrochemical facilities [53]. It can also analyze the risk of chemical transport. Safeti analyzes complex consequences from accident scenarios and takes meteorological conditions and population distributions into account when quantifying the risk of the hazardous chemical. The output of Safeti are: individual risk contours, societal curves and rankings of risk contributors. Risk results can be laid over digitized maps and satellite photos, which could be beneficial when analyzing a route. Safeti is widely used because it performs all the analytical and data processing and produces QRA results within a structured framework. The Safeti software is based on the principles and standards in the Dutch Purple Book [7].

\section{A.3.2 Safeti Offshore}

Safeti Offshore is a formal, structured and systematic approach for conducting an offshore QRA analysis, developed by DNV GL [53]. This is applicable to fixed, floating, ship shaped facilities and accounts for the influence of a vast array of offshore safety systems and barriers (e.g., isolation, blowdown, blast and fire walls). Safeti offshore can also model sub-sea releases, perform a detailed escalation analysis and contains other models to analyze offshore installations.

\section{A.3.3 Safeti Chemical Transport Risk Analysis}

The Safeti Chemical Transport Risk Analysis Software provides a holistic picture of risk using QRA to analyze the transport of hazardous chemicals [7]. This software can evaluate rail-specific transportation and analyze factors along the route (population density, weather, etc.) as needed. Safeti can help identify areas along a route that may need specific mitigations (e.g. speed) and optimum transport routes. For the transport of LNG on rail, this software is probably the most applicable.

\section{A.3.4 RISKCURVES}

RISKCURVES is a comprehensive quantitative risk analysis software which analyzes the risk to the surrounding population from the storage and transport of hazardous material, developed by Gexcon [7]. Calculated risks are expressed in terms of individual, societal and consequence-only 
risks, including in individual risk contours, societal risk curves, and risk ranking points. The RISKCURVES software is based on the principles and standards in the Dutch Purple Book [7].

\section{A.3.5 Shepherd}

Shepherd is a QRA tool for the company Royal Dutch Shell for onshore facilities and operations, available exclusively through Gexcon [54]. Shepherd has been continuously developed and validated by Shell since the 1990s. The FRED software, Shell's consequence modeling tool, integrates its results with Shepherd. Shepherd allows fast and reliable prediction of risk related to incidents, such as the release of flammable or toxic fluid, fires and explosions. 


\section{Appendix B. Risk Criteria Benchmark Values}

A literature search was done to explore examples of risk acceptability criteria used around the world in various industries. This was done to benchmark and provide context for the recommendations given above. Additional details from this survey are included here for reference.

\section{B.1 Risk Acceptability Criteria Survey}

Analyzing risk acceptance criteria from other countries and applications provides a basis for understanding the level of risk accepted worldwide. Compiling quantitative decision-making criteria used in risk assessment demonstrates the range of acceptability levels of risk and different ways to apply risk acceptance criteria. Generally, most industries apply individual and societal risk acceptability criteria, but cost-benefit or qualitative criteria using ALARP principles is also utilized. These examples are intended to demonstrate the variety of how risk acceptability criteria can be applied.

The multi-national corporation DNV GL which provides risk management services to maritime, oil and gas, and power and renewable industries published a report analyzing the feasibility of defining and using harmonized risk acceptance criteria in decision making for dangerous goods transportation. The report contacted 232 experts, representatives of the European Union (EU) Member States plus Norway and Switzerland and representatives of the transport and dangerous goods industries [45]. The report concluded that the transport of dangerous goods is not managed in a consistent way between EU states. Based on the lack of consensus, the report proposed a harmonized approach to developing risk acceptance criteria, including [45]:

1. Threshold criteria, expressed as an expectation value of fatalities per year. Below this, detailed risk assessment and further risk reduction would not be required.

2. Individual risk criteria, expressed as maximum acceptable risks of death per year for the most exposed individuals. Above this, the risk would not be acceptable.

3. Societal risk criteria, expressed as FN curves for the most exposed communities. Above this, measures to reduce catastrophe risk should be investigated.

4. Scrutiny level, expressed as an expectation value of fatalities per tonne of dangerous goods transported over a route. Above this, justification of the transport would be needed, and additional restrictions or safety measures should be investigated.

5. As low as reasonably practicable (ALARP) criteria, consisting of either qualitative or cost-benefit criteria for evaluation of additional restrictions or safety measures.

6. Improvement target for transportation of dangerous goods, expressed as an expectation value of fatalities per year from all modes of transportation of dangerous goods. This would be used to monitor performance and propose additional restrictions or safety measures. This risk acceptance criterion is aimed at focusing future improvement efforts.

7. Improvement target for dangerous goods, expressed as an expectation value of fatalities per year from all production and transport of dangerous goods. This would be a possible 
way of monitoring and improving consistency with requirements for fixed installations

This risk acceptance criterion is aimed at focusing future improvement efforts.

The report also concluded that harmonized risk acceptance criteria should be guidelines rather than rigid rules because of the different treatments of regulating risk amongst the Member States. This example is included here to demonstrate the types of risk acceptance criteria, both qualitative and quantitative, could be applied to the transport of LNG on rail.

\section{B.2 Individual Risk}

As discussed in Section 2.3.1, individual risk is the risk posed to a single individual. Individual risk criteria are used to determine if an activity is within an acceptable range of risk for a single individual. This acceptability varies with involuntary and voluntary risk activities as well as countries' culture of accepting risk. Individual risk can be calculated in several ways, but it is most commonly expressed as an annual probability. Individual risk plays a major role in regulating health and safety in many countries, including the U.S. Several examples of ways individual risks are calculated and/or compared are included below.

\section{B.2.1 U.S. Nuclear Regulatory Commission (NRC)}

The U.S. NRC has been on the forefront of developing risk criteria for decades. The NRC has two safety objectives, based on the principles that nuclear risks should not be a significant addition to other societal risks [4]. The qualitative goals are:

1. Individual members of the public should be provided a level of protection from the consequences of nuclear power plant (NPP) operation such that individuals bear no significant additional risk to life and health.

2. Societal risks to life and health from NPP operation should be comparable to or less than the risks of generating electricity by viable competing technologies and should not be a significant addition to other societal risks.

The quantitative individual risk goal is that fatalities from reactor accidents should not exceed 0.1 percent of the sum of prompt fatality risks to which members of the population are generally exposed. At the time the NRC established this policy in 1983, the individual fatality risk in the U.S. from all accidents was approximately $5 \times 10^{-4} / \mathrm{yr}$, meaning that the NRC individual risk limit is $5 \times 10^{-7}$ fatalities/year [4].

\section{B.2.2 Transportation of Dangerous Goods}

The first use of risk assessment for railways in the Netherlands was in connection with the transport of dangerous goods [46]. Rail transport of dangerous goods typically produced low individual risks near to the route, but large societal risks spread over the length of the route, particularly in densely populated areas [46]. Included in this report are examples from different countries on risk acceptance criteria and an approach to developing risk acceptance criteria.

The Netherlands' Committee for the Prevention of Disasters (Commissie Preventie van Rampen $[\mathrm{CPR}]$ ) created an individual risk criteria for transportation of dangerous chemicals by road, railroad cars or inland waterways of $1 \times 10^{-6}$ fatalities per year, which is equal to their risk acceptance criterion for stationary activities [47]. 


\section{B.2.3 Marine Transport Risk}

The risk acceptance criteria for marine transport is included because it pertains to fixed facility and transportation of hazardous materials. Included here is an example of risk acceptance criteria for this industry.

The International Maritime Organization (IMO) published guidelines for "Formal Safety Assessment (FSA) for Use in the IMO Rule-Making Process" to create a tool to evaluate new regulations for maritime safety and to compare between existing and new regulations [48]. These guidelines discuss the comparison between societal and individual risk and concludes that it is necessary to look at both types of risk for a full picture. For individual risk, the guidelines state that an appropriate level for risk criteria is to be substantially below the total accidents risk in daily life but might be similar to risks accepted from other involuntary sources. Table B-1 provides an example for individual risk acceptance criteria, however the document states that specific values should be selected appropriately.

Table B-1. IMO quantitative risk evaluation upper and lower bounds [48]

\begin{tabular}{|l|l|l|l|}
\hline \multicolumn{2}{|c|}{ Decision Parameter } & \multicolumn{2}{l|}{ Acceptance Criteria } \\
\cline { 3 - 4 } \multicolumn{2}{|l|}{} & Lower bound for ALARP region & $\begin{array}{l}\text { Upper bound for } \\
\text { ALARP region }\end{array}$ \\
\cline { 3 - 4 } & $\begin{array}{l}\text { Negligible (broadly acceptable) } \\
\text { fatality risk per year }\end{array}$ & $\begin{array}{l}\text { Maximum acceptable } \\
\text { fatality risk per year }\end{array}$ \\
\hline \hline \multirow{2}{*}{ Individual Risk } & To crew member & $10-^{6}$ & $10-^{3}$ \\
\cline { 2 - 4 } & To passenger & $10-^{6}$ & $10-^{4}$ \\
\cline { 2 - 4 } & $\begin{array}{l}\text { To third parties, members of } \\
\text { public ashore }\end{array}$ & $10-^{6}$ & $10-^{4}$ \\
\cline { 2 - 4 } & Target values for new ships & $10-^{6}$ & $\begin{array}{l}\text { Above values to be } \\
\text { reduced by one order of } \\
\text { magnitude }\end{array}$ \\
\hline Societal Risk & To groups of above persons & $\begin{array}{l}\text { To be derived by using economic } \\
\text { parameters }\end{array}$ & \\
\hline
\end{tabular}

\section{B.2.4 Fixed Facility Risk}

The risk acceptance criteria for fixed facility is centered around industrial activities involving dangerous goods or processes. Although this criterion often excludes transportation activities, it is included because the consequences of LNG fixed installations are pertinent and the risk acceptance criteria in general seeks to limit the consequences of major accidents using risk acceptance criteria.

The NFPA 59A, the Standard for the Production, Storage, and Handling of Liquefied Natural Gas, contains a chapter on conducting a performance-based LNG plant siting using QRA [8]. This standard is applicable because it specifically addresses the hazard, the use and transport of LNG. As part of this analysis, individual risk acceptability criteria were specified. 
Table B-2. NFPA 59A Criteria for acceptability of individual risk (IR) of fatality [8]

\begin{tabular}{ll}
\hline Criterion Annual Frequency & Permitted Developments \\
\hline \hline Zone 1: IR $>5 \times 10^{-5}$ & $\begin{array}{l}\text { All land uses under the control of the plant operator or } \\
\text { subject to an approved legal agreement }\end{array}$ \\
\hline Zone 2: $3 \times 10^{-7} \leq \mathrm{IR} \leq 5 \times 10^{-5}$ & $\begin{array}{l}\text { General public areas excluding sensitive establishments } \\
\text { (including but not limited to schools, daycare facilities, } \\
\text { hospitals, nursing homes, jails and prisons) }\end{array}$ \\
\hline Zone 3: IR $<3 \times 10^{-7}$ & No restrictions \\
\hline
\end{tabular}

Table B-3. NFPA 59A Criteria for acceptability of individual risk of irreversible harm [8]

Criterion Annual Frequency Permitted Developments

\begin{tabular}{ll}
\hline \hline Zone 1: IR $>5 \times 10^{-4}$ & $\begin{array}{l}\text { All land uses under the control of the plant operator or } \\
\text { subject to an approved legal agreement }\end{array}$ \\
\hline
\end{tabular}

\begin{aligned} \hline Zone $2: 3 \times 10^{-6} \leq \mathrm{IR} \leq 5 \times 10^{-4} & \begin{array}{l}\text { General public areas excluding sensitive establishments } \\ \text { (including but not limited to schools, daycare facilities, }\end{array} \\ &$ hospitals, nursing homes, jails and prisons) \end{aligned}

Zone 3: IR $<3 \times 10^{-6} \quad$ No restrictions

Other jurisdictions outside the U.S. are useful for comparing risk acceptability, though the examples below are primarily for land-use and development risk (i.e., fixed facility).

Hong Kong individual risk guidelines are set by an Inter-Departmental Coordinating Committee (CCPHI) and published in in the Hong Kong Planning Standards and Guidelines [55], and in a Technical Memorandum on the Environmental Impact Assessment Ordinance [56]. These guidelines require that the off-site individual risk associated with a hazardous installation should not exceed $10^{-5}$ fatalities per year [46].

The Netherlands' maximum acceptable individual risk value $10^{-6}$ fatalities/year is an environmental quality requirement in the External Safety Decree for Establishments [47]. The environment protection act enables the establishment of absolute limit values; thus, risk acceptability can be regulated by having a limit for individual risk. Only one QRA software tool was allowed for QRA calculations for land use purposes: Safeti, which is discussed in Appendix A, Section A.3.1.

Belgium uses a risk-based approach to land-use planning, directed by regional authorities who are responsible for policies [49]. The risk criteria for external human risks includes both individual and societal risks. For individual risks [49]:

- Border of the facility: $10^{-5}$ fatalities per year

- Border of residential area: $10^{-6}$ fatalities per year

- Border of area containing vulnerable location: $10^{-7}$ fatalities per year 
The Australian New South Wales Department of Planning documented an integrated approach to assessing hazardous development. The assessment of the safety of the location of a proposed development is based on individual fatality risk criteria in Table B-4 [50]. The document also contains levels of effects that may cause injury but not necessarily fatality for heat radiation, explosion overpressure, and toxic exposure criteria.

Table B-4. New South Wales Individual Facility Risk Criteria

\begin{tabular}{lc}
\hline Land Use & Suggested Criteria \\
\hline \hline Hospitals, schools, child-care facilities, old age housing & $5 \times 10^{-7}$ fatalities per year \\
\hline Residential, hotels, motels, tourist resorts & $1 \times 10^{-6}$ fatalities per year \\
\hline $\begin{array}{l}\text { Commercial developments including retail centers, offices } \\
\text { and entertainment centers }\end{array}$ & $5 \times 10^{-6}$ fatalities per year \\
\hline Sporting complexes and active open space & $1 \times 10^{-5}$ fatalities per year \\
\hline Industrial & $5 \times 10^{-5}$ fatalities per year \\
\hline
\end{tabular}

\section{B.3 Societal Risk}

As discussed in Section 2.3.2, societal risk is the risk posed to a group. Like individual risk, societal risk criteria are used by a regulator to determine if an activity is within an acceptable range of risk. However, contrary to individual risk, societal risk is usually assumed to be involuntary risk. Societal risk is typically expressed in an F-N curve, with the horizonal axis designating the number of fatalities $(\mathrm{N})$ and the vertical axis the annual frequency of exceeding $\mathrm{N}$ fatalities (F). Several examples of accepted societal risks included below.

\section{B.3.1 Transportation of Dangerous Goods}

In the UK, risk criteria for the transport of dangerous goods was developed by the Advisory Committee on Dangerous Substances who developed societal risk criteria for communities near roads, railways, and ports [46]. The risk criteria are shown below and illustrated in Figure B-1:

- Intolerable risk:

$$
\begin{aligned}
& \mathrm{F}>0.1 / \mathrm{N} \\
& \mathrm{F}<10^{-4} / \mathrm{N}
\end{aligned}
$$

- Negligible risk:

In Switzerland, the Ordinance on Protection Against Major Accidents required assessment of risks to the public and the environment from dangerous goods transport and fixed installations [46]. The Swiss Federal Office for the Environment published the following societal risk criteria:

- Intolerable risk:

$$
\begin{aligned}
& \mathrm{F}>10^{-3} / \mathrm{N}^{2} \text { for } 10 \leq \mathrm{N} \leq 10,000 \text { fatalities } \\
& \mathrm{F}<10^{-5} / \mathrm{N}^{2} \text { for } 10 \leq \mathrm{N} \leq 1,000 \text { fatalities }
\end{aligned}
$$

- Negligible risk:

The criteria, illustrated in Figure B-1, were applied to fixed installations and to $100 \mathrm{~m}$ sections of road tunnels [46]. This is different than the UK criteria above, which applied the risk to geographical communities near a route rather than specific lengths of tunnels.

The societal risk criteria for transportation of dangerous chemicals by road, railroad cars, or inland waterways in the Netherlands is $10^{-4}$ per year per $\mathrm{km}$ of transport route for the frequency to cause an accident with 10 or more fatalities and $10^{-6}$ per year per km of transport route for the frequency to cause an accident with 100 or more fatalities, and so on [47]. This is displayed on the F-N curve in Figure B-1. This risk criteria is normalized per kilometer of track, which 
implies that $100 \mathrm{~m}$ of transport route is given the same risk criterion as a fixed installation [46]. Additionally, this analysis is only performed to the highest-risk kilometer of the route, which itself is determined through a simplified analysis of affected area and population density [46]. By only analyzing a single kilometer, this could miss important aggregate effects; if there are multiple areas of potentially high consequence in a route, but only the highest-risk is analyzed, the societal risk of the other kilometers is ignored in the analysis.

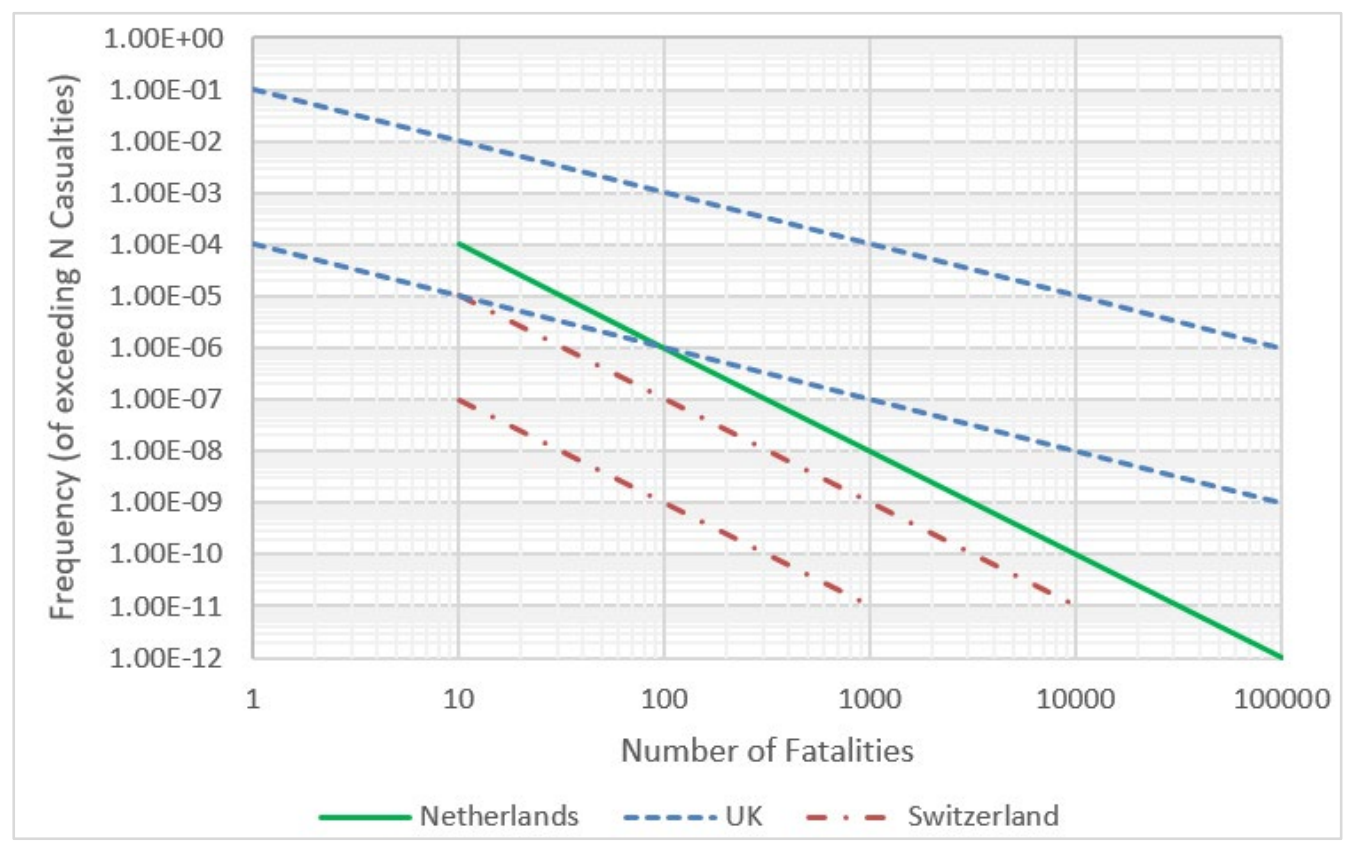

Figure B-1. Societal risk values for the transport of dangerous goods

\section{B.3.2 Marine Transport Risk}

The IMO published guidelines for "Formal Safety Assessment (FSA) for Use in the IMO RuleMaking Process" also recommend defining societal risk acceptance criteria for different ship types and/or marine activities, as illustrated in Figure B-2 [48] with different criteria for Tankers (left) than for bulk and ore carriers and container vessels (right). The document recommends using a F-N slope of -1 on a $\log / \log$ scale to reflect a risk averse attitude. 

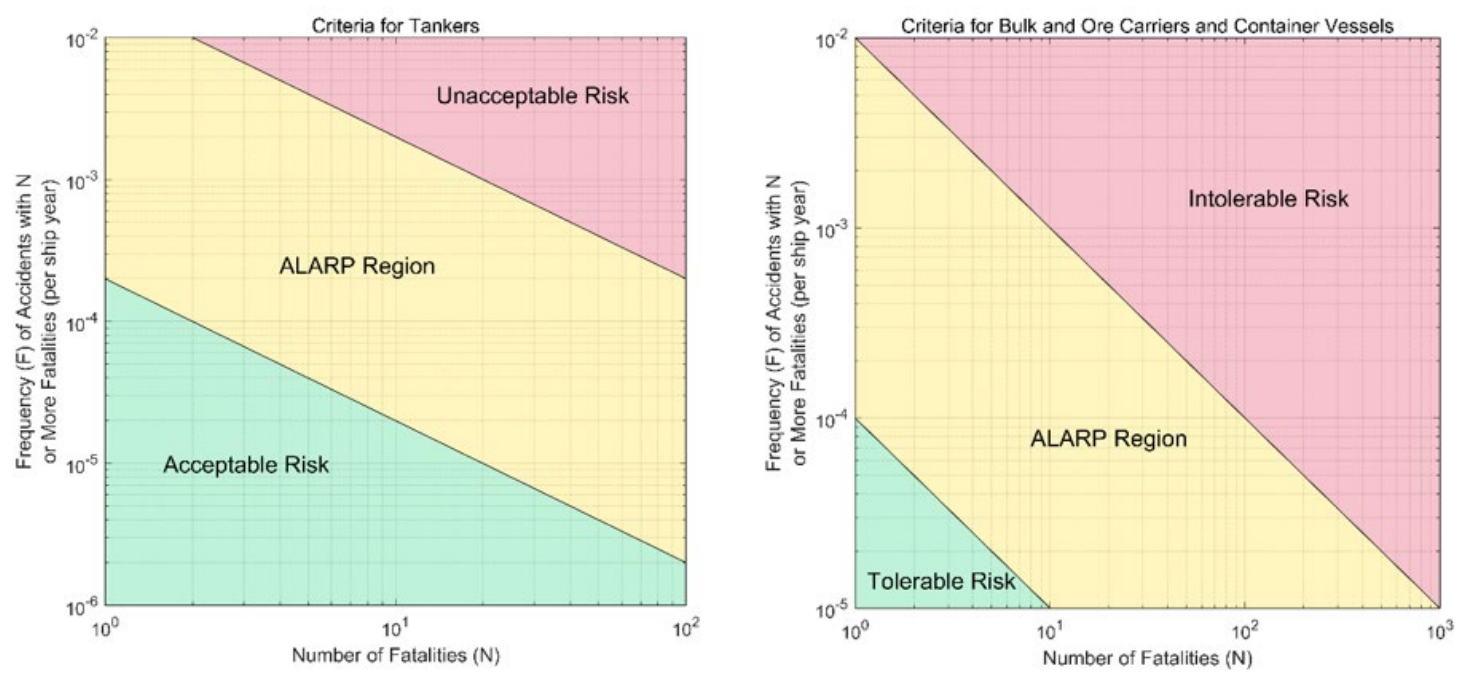

Figure B-2. FN-Diagram example [48]

\section{B.3.3 Fixed Facility Risk}

The NFPA 59A, the Standard for the Production, Storage, and Handling of Liquefied Natural Gas, also specifies societal risk acceptability criteria as part of conducting a quantitative risk assessment for a LNG plant [8]. The societal risk criteria are shown in Figure B-3 and Figure B4.

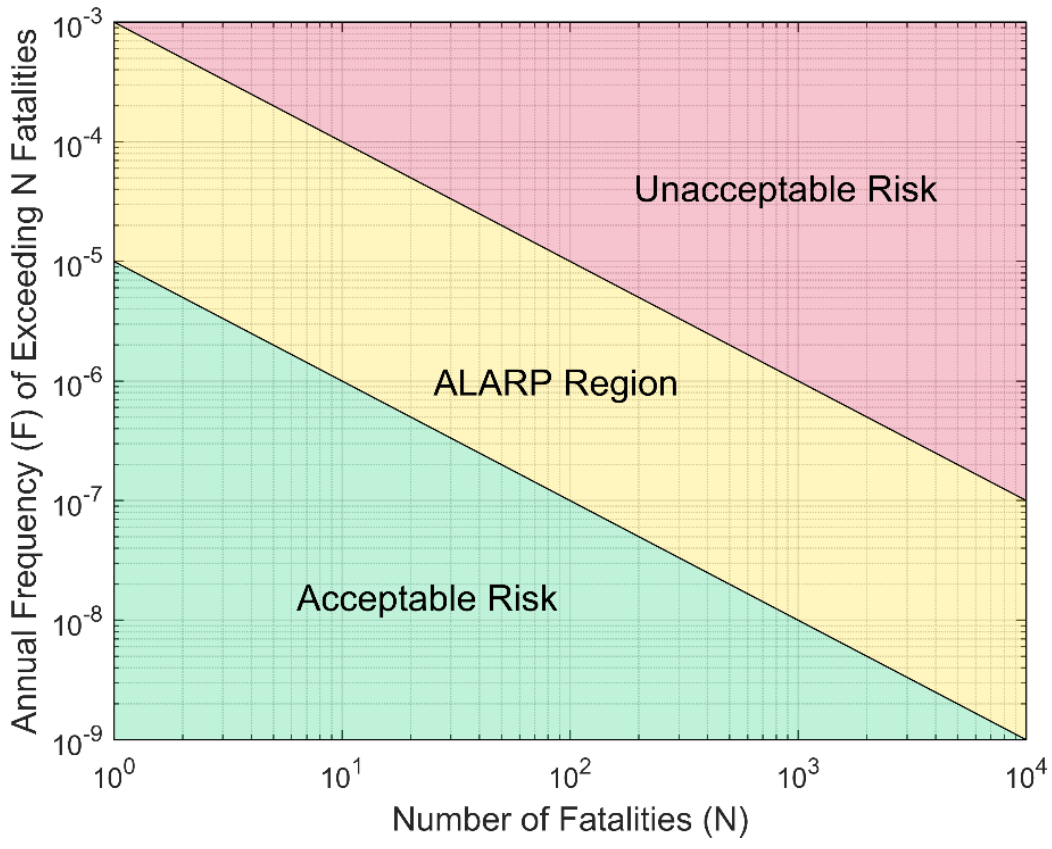

Figure B-3. NFPA 59A acceptability regions of societal fatality risk in the F-N domain [8] 


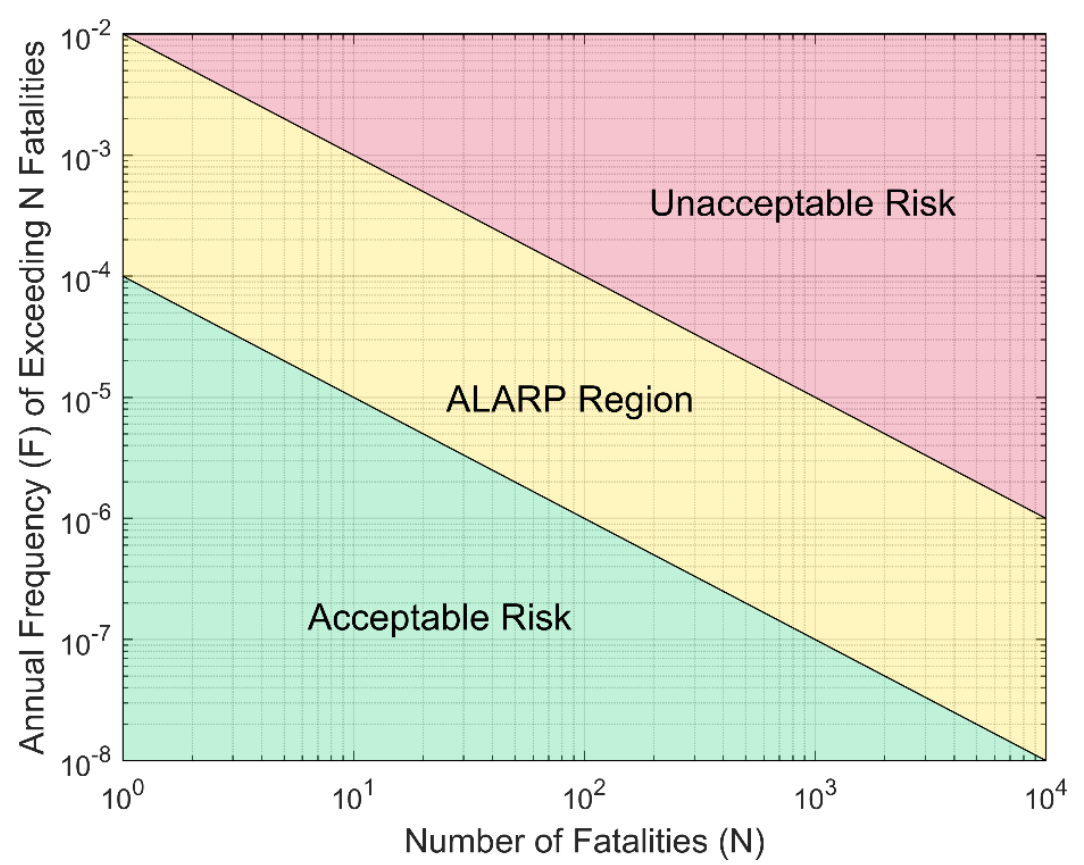

Figure B-4. NFPA 59A acceptability regions of societal irreversible harm risk in the F-N domain [8]

Hong Kong societal risk guidelines for hazardous installations are presented graphically in Figure B-5 which expresses risks to the whole population [46]. The maximum acceptable risk is $\mathrm{F}=10^{-3} / \mathrm{N}$ for $1 \leq \mathrm{N} \leq 1,000$. Risks below this maximum acceptable line should be reduced to as low as reasonably practicable (ALARP) before they are considered acceptable. Accidents involving more than 1,000 fatalities are unacceptable. 


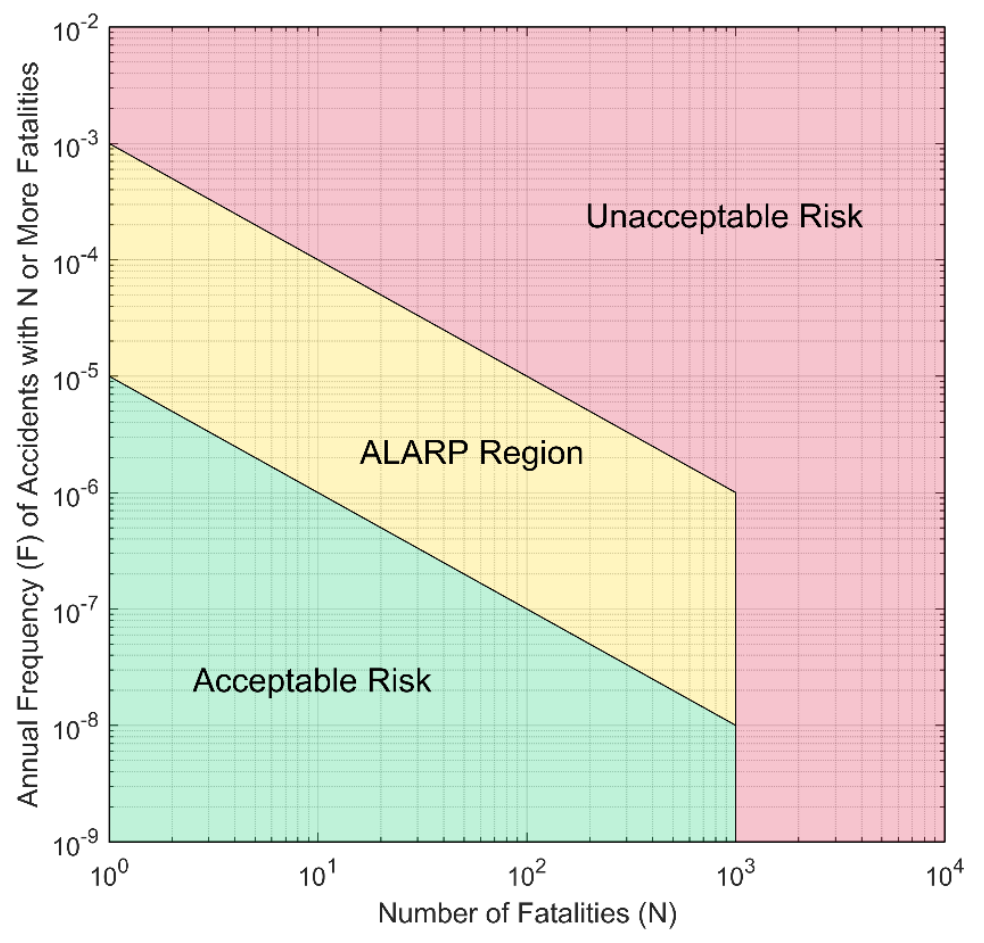

Figure B-5. Hong Kong government risk guidelines [57]

The Netherlands' societal risk criteria for fixed installations is $10^{-3} / \mathrm{N}^{2}$ per year, which is the maximum probability per year that would be acceptable for any accident at an establishment that would cause more than $\mathrm{N}$ lethal victims outside the establishment [47]. This is shown in Figure B-6.

Belgium regional authorities' maximum acceptable societal risk for installations is expressed on an F-N diagram as $\mathrm{F}=0.01 / \mathrm{N}^{2}$ for $10 \leq \mathrm{N} \leq 1,000$ [49] in Figure B-7. No accidents are permitted with $\mathrm{N}>1,000$ fatalities, excluding people working at the establishment itself [49]. 


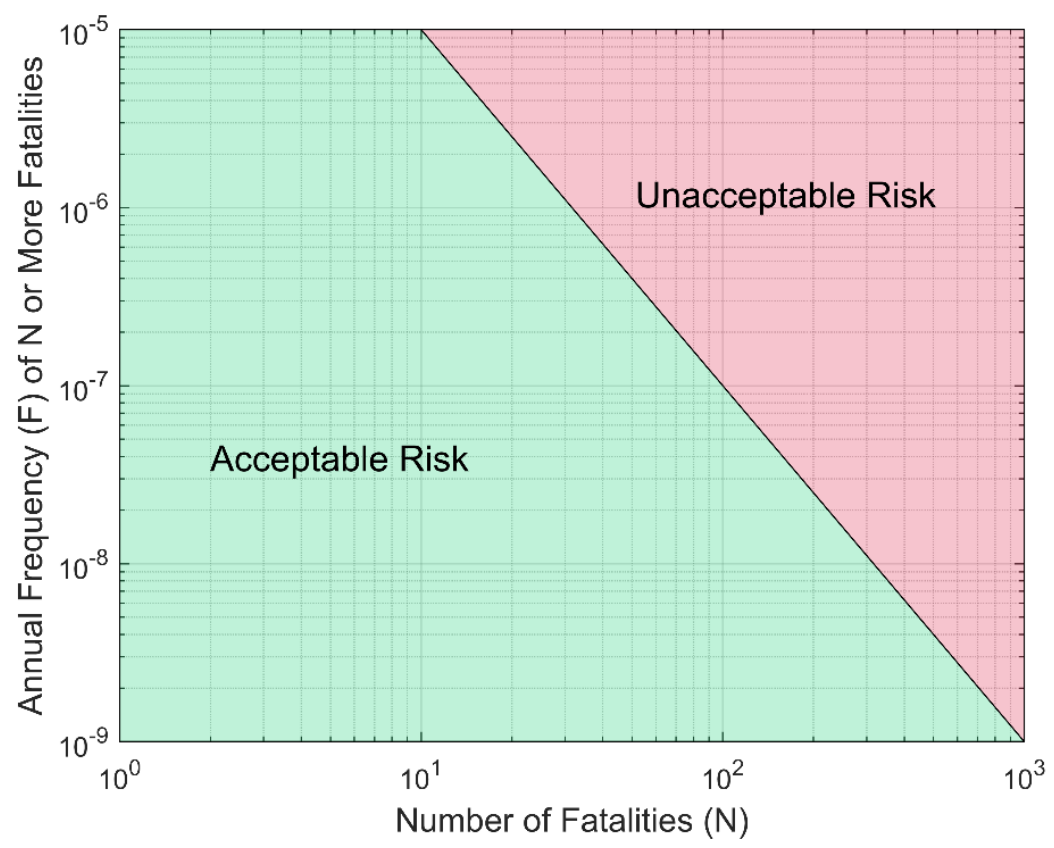

Figure B-6. Netherlands societal risk fixed facility criteria

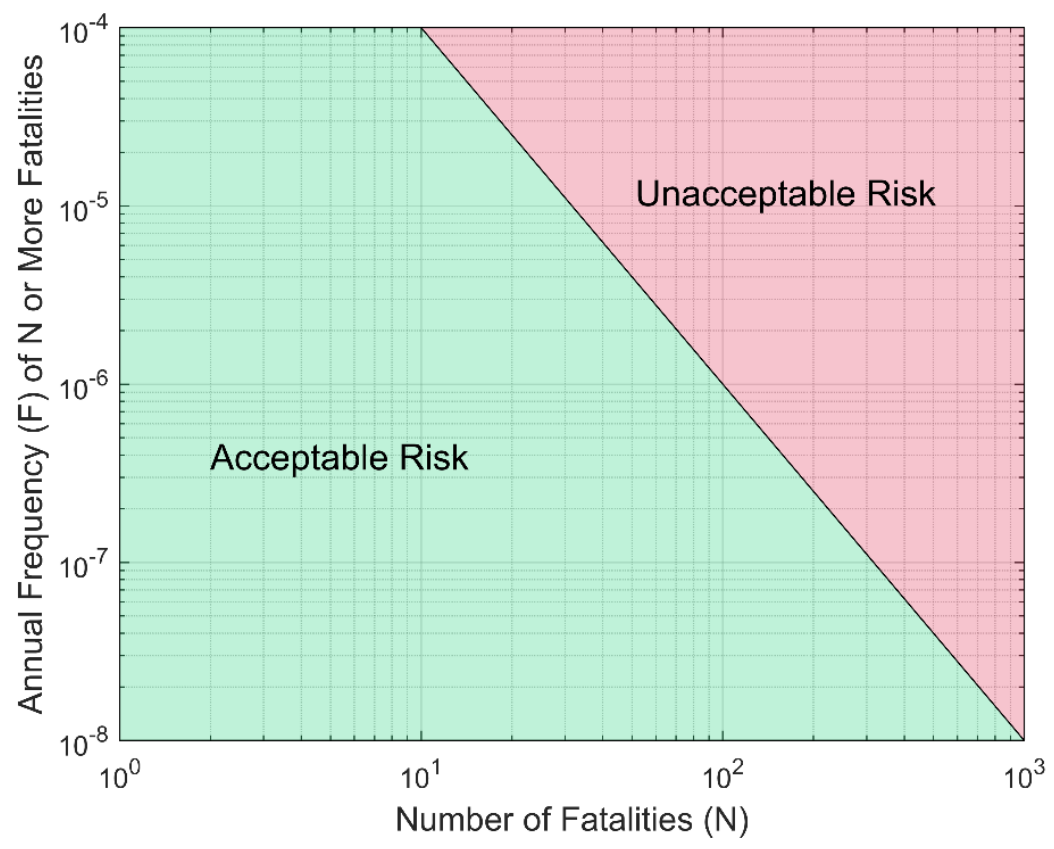

Figure B-7. Belgium societal risk criteria

The Australian New South Wales Department of Planning's document on assessing hazardous development also included criteria for addressing societal concerns arising where there is a risk of multiple fatalities occurring in one event, illustrated in Figure B-8 [50]. 


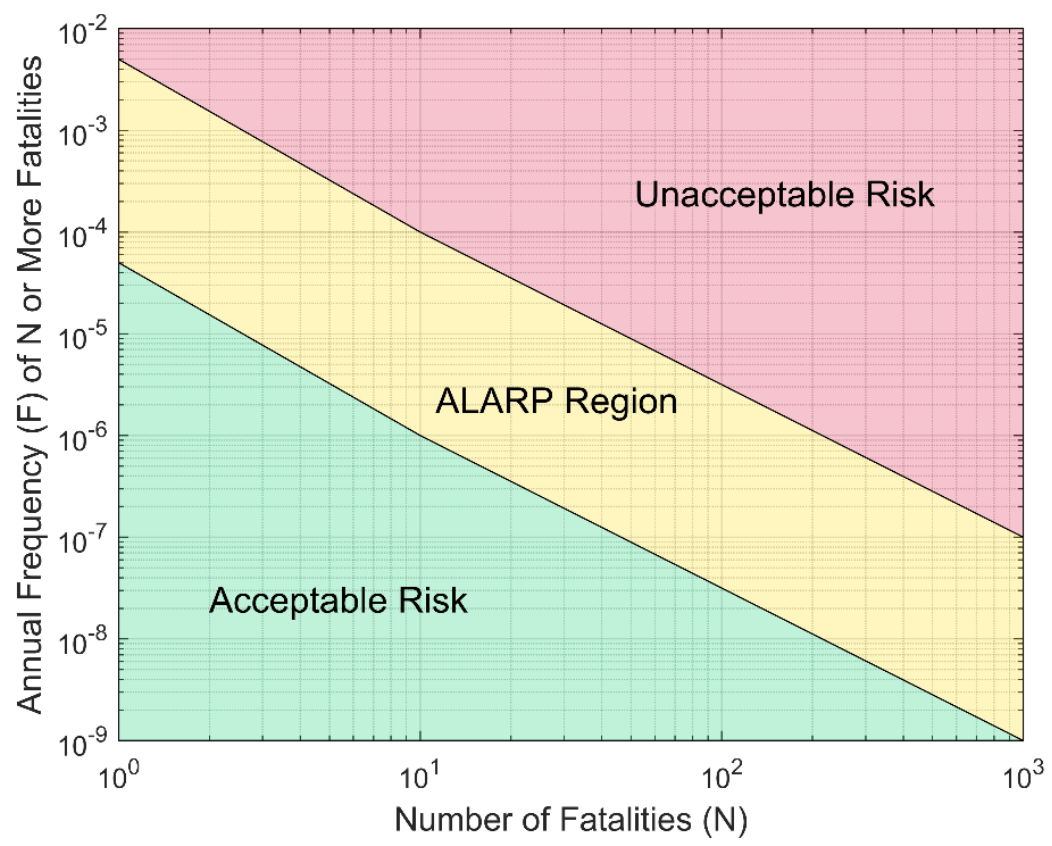

Figure B-8. New Wales planning department societal risk criteria

\section{B.4 Qualitative Risk}

There are various methods for how quantitative risk results can be used qualitatively to analyze a hazard. Examples of qualitative risk metrics are included below.

The United Nations Economic Commission for Europe compiled guidance on land-use planning and siting of hazardous activities for selected countries that have a well-established framework [49]. The French land-use planning approach considers the occurrence probability of representative scenarios and the consequence analysis in a matrix form [49]. The probability classes and their associated qualitative and quantitative frequencies are shown in Table B-5 and gravity levels, or intensity or magnitude of the effects, are shown in Table B-6. The resulting risk matrix which is used to evaluate land-use plans is illustrated in Figure B-9.

Table B-5. Probability classes for French land use planning

\begin{tabular}{llll}
\hline $\begin{array}{l}\text { Frequency } \\
\text { Class }\end{array}$ & & \multicolumn{1}{c}{ Qualitative Frequency } & $\begin{array}{c}\text { Quantitative } \\
\text { Frequency }\end{array}$ \\
\hline \hline $\mathrm{A}$ & Frequent & $\begin{array}{l}\text { Already occurred several times during } \\
\text { the lifetime of the facility }\end{array}$ & $<10^{-1}$ event/year \\
\hline $\mathrm{B}$ & Probable & $\begin{array}{l}\text { Already occurred during the lifetime of } \\
\text { the facility }\end{array}$ & $<10^{-2}$ event/year \\
\hline $\mathrm{C}$ & Improbable & $\begin{array}{l}\text { Already occurred in a similar facility } \\
\text { worldwide }\end{array}$ & $<10^{-3}$ event/year \\
\hline $\mathrm{D}$ & $\begin{array}{l}\text { Realistic but } \\
\text { unlikely }\end{array}$ & $\begin{array}{l}\text { Possible but never occurred in a similar } \\
\text { facility }\end{array}$ & $<10^{-4}$ event/year \\
\hline
\end{tabular}




\begin{tabular}{llll}
\hline $\begin{array}{l}\text { Frequency } \\
\text { Class }\end{array}$ & & Qualitative Frequency & $\begin{array}{c}\text { Quantitative } \\
\text { Frequency }\end{array}$ \\
\hline \hline $\mathrm{E}$ & $\begin{array}{l}\text { Extremely } \\
\text { unlikely }\end{array}$ & $\begin{array}{l}\text { Possible considering current knowledge, } \\
\text { but never occurred anywhere worldwide }\end{array}$ & $<10^{-5}$ event/year \\
& & & \\
\hline
\end{tabular}

Table B-6. Gravity levels expressed in relation to number of people exposed for French land use planning

\begin{tabular}{|c|c|c|c|}
\hline Gravity Level & $\begin{array}{l}5 \% \text { Lethal } \\
\text { Effects }\end{array}$ & 1\% Lethal Effects & $\begin{array}{l}\text { Irreversible } \\
\text { Effects }\end{array}$ \\
\hline Disastrous & More than 10 & More than 100 & More than 1000 \\
\hline Catastrophic & $1-10$ & $10-100$ & $100-1000$ \\
\hline Major & 1 & $1-10$ & $10-100$ \\
\hline Serious & 0 & 1 & $1-10$ \\
\hline Moderate & 0 & 0 & Less than 1 \\
\hline
\end{tabular}

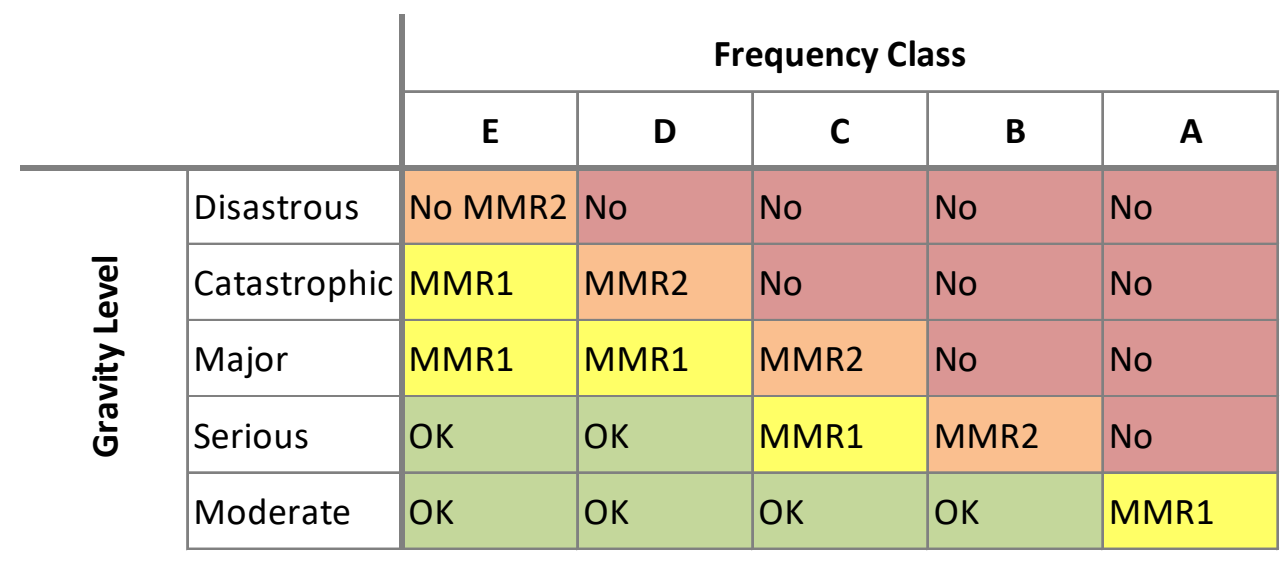

Red (NO): unacceptable risk green (OK): acceptable risk orange (No for the future/MMR2 for existing buildings): no more than five dangerous phenomena can be placed in these cells after the operator has taken all measures to reduce the risk yellow (MMR1): a permit to operate a hazardous facility can be issued after all practicable safty measure have been implemented

Figure B-9. French risk acceptability matrix for land-use planning evaluations in relation to the presence of hazardous materials [49]

The European Railway Agency developed Common Safety Targets, to harmonize the evaluation of updates to the railway system across Europe [58]. EU Regulation 402/2013 states that the proposer shall consider the impact of the change in question on the safety of the railway system [58]. The risk acceptability of a significant change should be evaluated using one or more of the following risk acceptance principles: the application of codes of practice, a comparison with similar reference systems, or an explicit risk estimation [58]. The European Railway Agency amended this regulation to better harmonize risk acceptance criteria — or design targets - to 
assess the acceptability of risks arising from failures of technical system. The amended regulation does not give concrete risk acceptance criteria but instead regulates that compliance with applicable harmonized design targets should be demonstrated [59].

The London Underground safety objective is to make system risk ALARP and within acceptable limits, based on a structured qualitative evaluation [46]. To determine whether risks have been reduced ALARP, the following are needed: an assessment of the risk to be avoided, the sacrifice (e.g., money, time and trouble) involved in taking measures to avoid that risk, and a comparison of the two. The process can involve varying degrees of rigor depending on the hazard and mitigative measures. If the issue has a high safety significance, a qualitative assessment should be supported with a quantitative assessment.

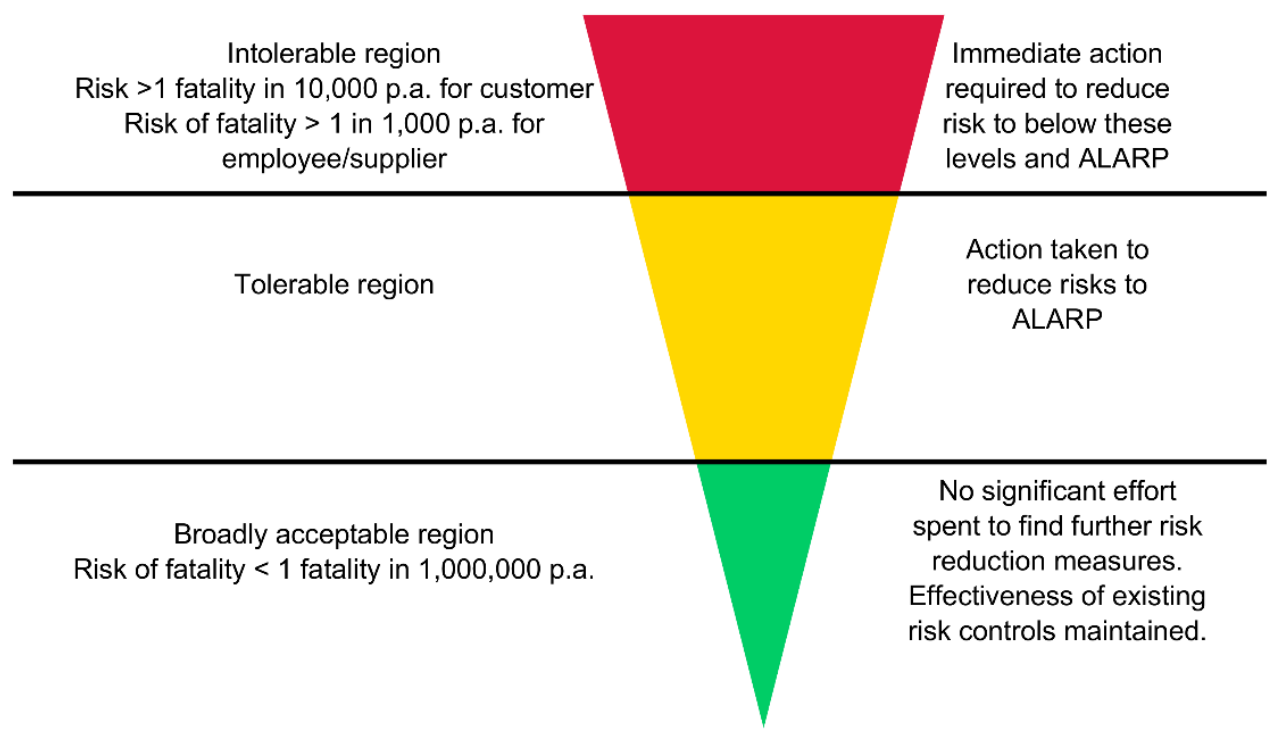

Figure B-10. London Underground acceptability of risk framework [46]

The UK's Health and Safety Executive (HSE) assess applications for hazardous facility by using consultation zones to represent the potentially significant consequences for human health, urban areas and major transport routes. The three zones include:

- A risk of $10^{-5}$ per year of a dangerous dose or worse as the "inner zone"

- A risk of $10^{-5}$ to $10^{-6}$ per year of a dangerous dose or worse as the "middle zone"

- A risk of $10^{-6}$ to $0.3 \times 10^{-7}$ as the "outer zone" [60]

The HSE is not consulted beyond the outer zones. Based on the zone calculated, the proposed development is classified into one of four "sensitivity levels" which determines whether or not a proposal is 'Advise Against' (AA), 'Don't Advise Against' (DAA), as shown in Table B-7.

Table B-7. HSE sensitivity zones [60]

\begin{tabular}{llll}
\hline \hline Level of Sensitivity & $\begin{array}{l}\text { Development } \\
\text { in Inner Zone }\end{array}$ & $\begin{array}{l}\text { Development } \\
\text { in Middle Zone }\end{array}$ & $\begin{array}{l}\text { Development } \\
\text { in Outer Zone }\end{array}$ \\
\hline \hline 1: Normal working population (Factories) & DAA & DAA & DAA \\
\hline 2: General Public (Houses) & AA & DAA & DAA \\
\hline
\end{tabular}




\begin{tabular}{llll}
\hline Level of Sensitivity & $\begin{array}{l}\text { Development } \\
\text { in Inner Zone }\end{array}$ & $\begin{array}{l}\text { Development } \\
\text { in Middle Zone }\end{array}$ & $\begin{array}{l}\text { Development } \\
\text { in Outer Zone }\end{array}$ \\
\hline \hline 3: Vulnerable members of society (Schools) & AA & AA & DAA \\
\hline $\begin{array}{l}\text { 4: Large and sensitive developments (Sports } \\
\text { stadiums) }\end{array}$ & AA & AA & AA \\
\hline $\begin{array}{l}\text { AA: Advise Against, DAA: Don't Advise } \\
\text { Against }\end{array}$ & & & \\
\hline
\end{tabular}

\section{B.5 Summary of Risk Acceptance Criteria}

Figure B-11 illustrates the different individual risk criteria. Figure B-12 summarizes the maximum acceptable societal risk criteria for different applications. Table B-8 summarizes individual risk acceptance criteria for applications with only one limit. Table B-9 and Table B-10 summarize individual risk acceptance criteria with upper and lower limits, respectively.

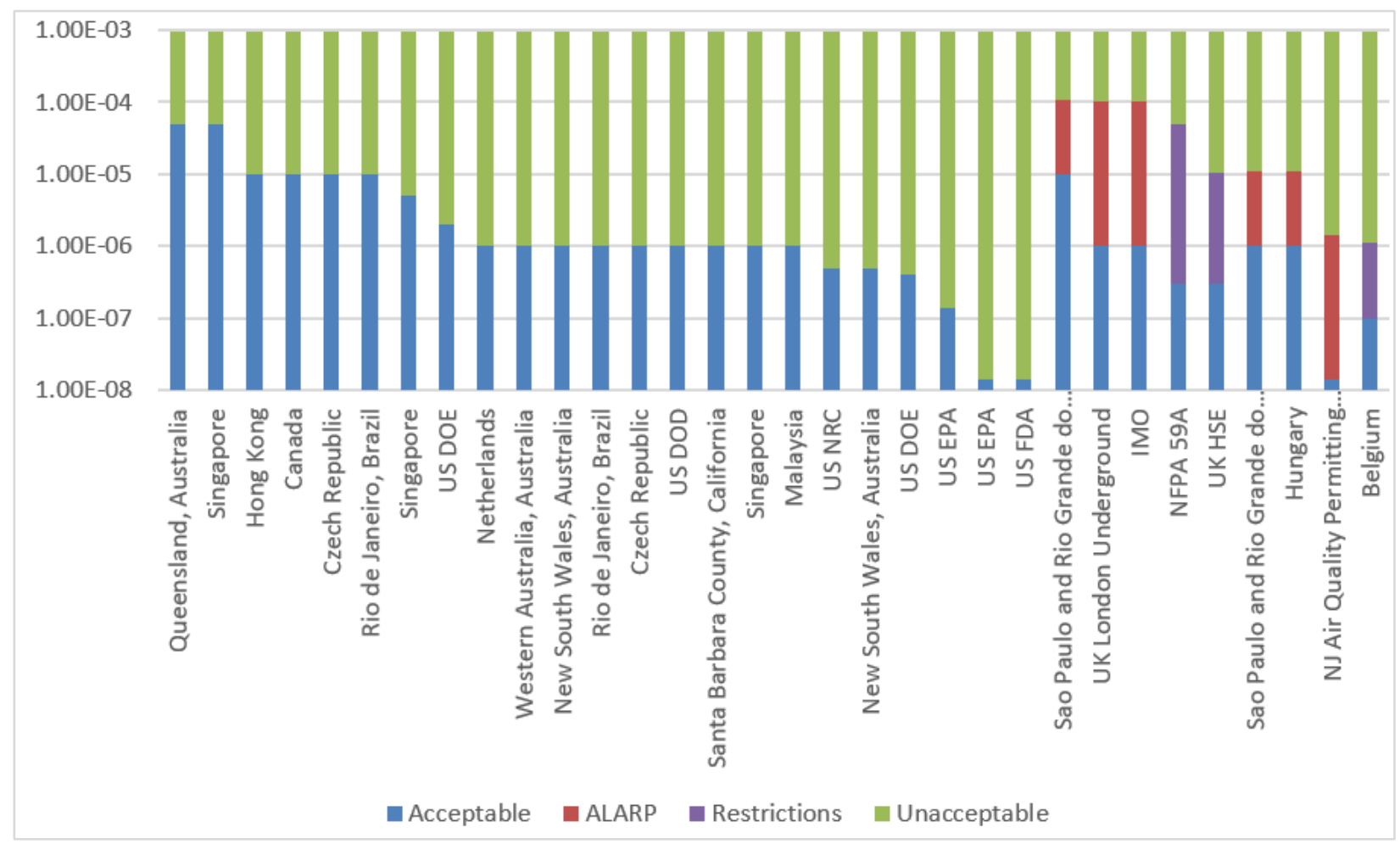

Figure B-11. Individual risk criteria 


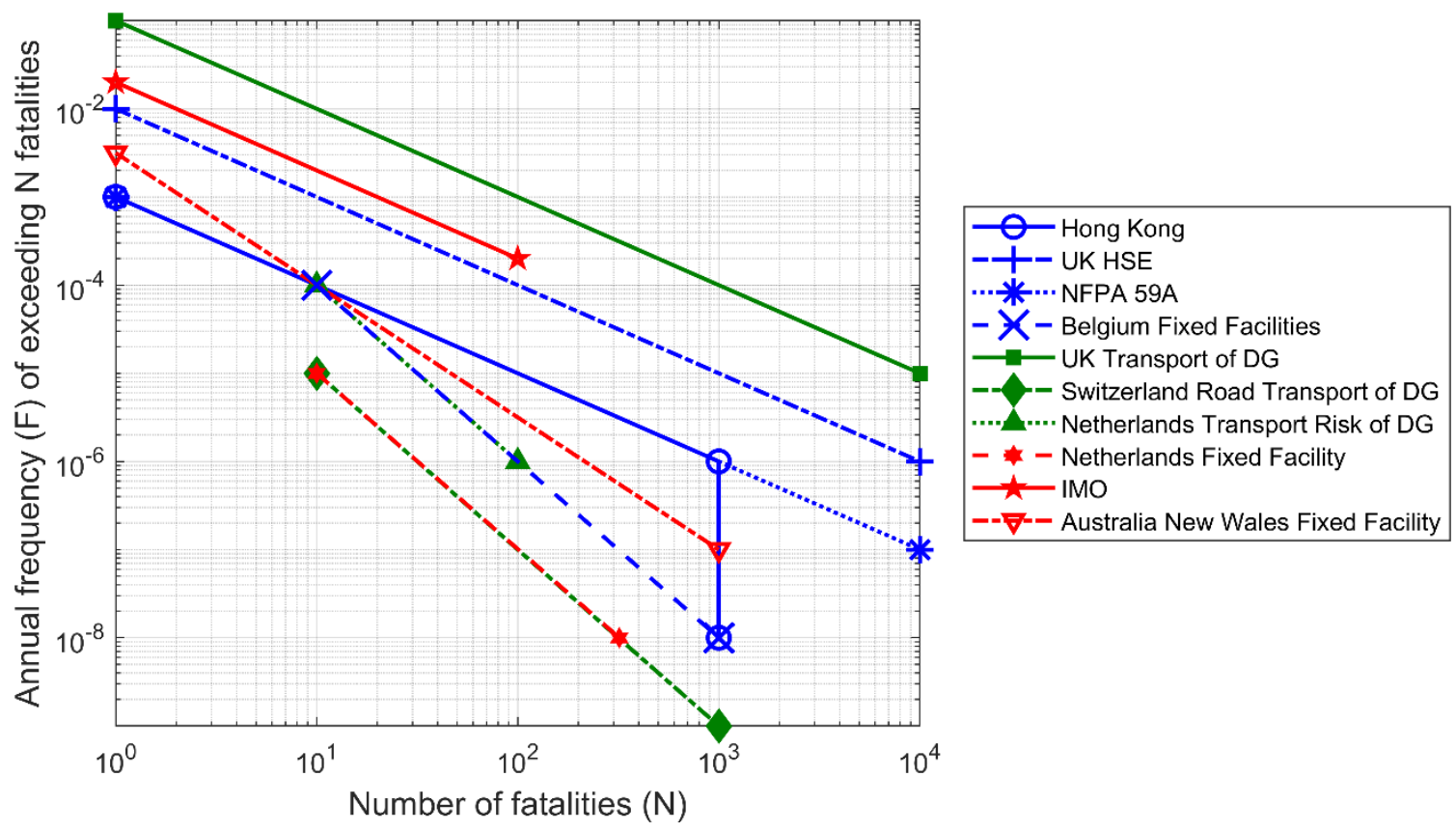

Figure B-12. Summary of maximum acceptable societal risk criteria 
Table B-8. Individual risk acceptance criteria for public with single limit

\begin{tabular}{|c|c|c|c|}
\hline $\begin{array}{c}\text { Individual } \\
\text { Risk Limit Per Year of } \\
\text { Exposure (Single Limit) }\end{array}$ & Entities & Application & Source \\
\hline \multirow[t]{2}{*}{$5 \times 10^{-5}$} & Australia, state of Queensland & Not extend beyond site boundary for new facilities & {$[27]$} \\
\hline & Singapore & Industrial developments & {$[27]$} \\
\hline \multirow[t]{5}{*}{$1 \times 10^{-5}$} & Hong Kong & New and existing installations & {$[46]$} \\
\hline & Canada & $\begin{array}{l}\text { Major Industrial Accidents Council of Canada } \\
\text { (MIACC), used for low density residential }\end{array}$ & {$[27]$} \\
\hline & Czech Republic & Existing installations & {$[27]$} \\
\hline & State of Rio de Janeiro, Brazil & Existing facilities & {$[27]$} \\
\hline & State of Rio de Janeiro, Brazil & Existing facilities & {$[27]$} \\
\hline $5 \times 10^{-6}$ & Singapore & Commercial developments & {$[27]$} \\
\hline $2 \times 10^{-6}$ & U.S. Department of Energy (DOE) & $\begin{array}{l}\text { Risk of latent cancer fatalities from nuclear facility } \\
\text { accidents }\end{array}$ & {$[27]$} \\
\hline \multirow[t]{9}{*}{$1 \times 10^{-6}$} & Netherlands & Environmental quality requirement & {$[47]$} \\
\hline & State of Western Australia, Australia & New installations, for non-sensitive exposures & {$[27]$} \\
\hline & State of New South Wales, Australia & Motels, tourist resorts & {$[50]$} \\
\hline & State of Rio de Janeiro, Brazil & Fixed installations and pipelines & {$[27]$} \\
\hline & Czech Republic & New facilities & {$[27]$} \\
\hline & U.S. Department of Defense (DoD) & Explosives handling activities & {$[27]$} \\
\hline & California, Santa Barbara County & & {$[27]$} \\
\hline & Singapore & General public & {$[27]$} \\
\hline & Malaysia & $\begin{array}{l}\text { Residential areas, schools, hospitals, and places of } \\
\text { continuous occupancy }\end{array}$ & {$[27]$} \\
\hline $5 \times 10^{-7}$ & U.S. NRC & Using accidental facility rate of $10^{-4}$ fatalities/year & [4] \\
\hline
\end{tabular}




\begin{tabular}{|l|l|l|c|}
\hline $\begin{array}{c}\text { Individual } \\
\text { Risk Limit Per Year of } \\
\text { Exposure (Single Limit) }\end{array}$ & \multicolumn{1}{|c|}{ Entities } & \multicolumn{1}{c|}{ Application } & Source \\
\hline & State of New South Wales, Australia & $\begin{array}{l}\text { Hospitals, schools, child-care facilities, old age } \\
\text { housing }\end{array}$ & {$[50]$} \\
\hline $4 \times 10^{-7}$ & U.S. DOE & $\begin{array}{l}\text { Risk of "prompt" fatalities from nuclear facility } \\
\text { accidents }\end{array}$ & {$[27]$} \\
\hline $1.4 \times 10^{-7}$ & $\begin{array}{l}\text { U.S. Environmental Protective } \\
\text { Agency (EPA) }\end{array}$ & Various regulations & {$[27]$} \\
\hline $1.4 \times 10^{-8}$ & EPA & Various regulations, cancer risk to public & {$[27]$} \\
\cline { 2 - 5 } & $\begin{array}{l}\text { U.S. Food and Drug Administration } \\
\text { (FDA) }\end{array}$ & Various regulations, cancer risk to public & {$[27]$} \\
\hline
\end{tabular}


Table B-9. Individual risk acceptance criteria for public with upper limit

\begin{tabular}{|c|c|c|c|}
\hline $\begin{array}{c}\text { Individual } \\
\text { Risk Limit Per Year of } \\
\text { Exposure (Single Limit) }\end{array}$ & Entities & Application & Source \\
\hline \multirow[t]{3}{*}{$1 \times 10^{-4}$} & $\begin{array}{l}\text { States of Sao Paulo and Rio Grande } \\
\text { do Sul, Brazil }\end{array}$ & Pipeline & {$[27]$} \\
\hline & UK London Underground & Rail customers, unacceptable risk above value & {$[46]$} \\
\hline & IMO & Passengers and public ashore & {$[48]$} \\
\hline $5 \times 10^{-5}$ & NFPA 59A & $\begin{array}{l}\text { Public areas excluding sensitive establishments. } \\
\text { Above this value, all land uses under control of plant } \\
\text { operator or subject to approved legal agreement }\end{array}$ & {$[8]$} \\
\hline \multirow[t]{3}{*}{$1 \times 10^{-5}$} & UK HSE & $\begin{array}{l}\text { Higher than this, considered "inner zone". Lower, } \\
\text { considered "middle zone". Used to determine } \\
\text { developments allowed. }\end{array}$ & {$[60]$} \\
\hline & $\begin{array}{l}\text { States of Sao Paulo and Rio Grande } \\
\text { do Sul, Brazil }\end{array}$ & New fixed installations & {$[27]$} \\
\hline & Hungary & & {$[27]$} \\
\hline $1.4 \times 10^{-6}$ & $\begin{array}{l}\text { New Jersey Air Quality Permitting } \\
\text { Program }\end{array}$ & Cancer risk & {$[27]$} \\
\hline $1 \times 10^{-6}$ & Belgium & Border of residential area & [49] \\
\hline
\end{tabular}


Table B-10. Individual risk acceptance criteria for public with lower limit

\begin{tabular}{|c|c|c|c|}
\hline $\begin{array}{c}\text { Individual } \\
\text { Risk Limit Per Year of } \\
\text { Exposure (Single Limit) }\end{array}$ & Entities & Application & Source \\
\hline $1 \times 10^{-5}$ & $\begin{array}{l}\text { States of Sao Paulo and Rio Grande do } \\
\text { Sul, Brazil }\end{array}$ & Pipeline & {$[27]$} \\
\hline \multirow[t]{5}{*}{$1 \times 10^{-6}$} & UK HSE & $\begin{array}{l}\text { Higher than this, considered "middle zone". Lower, } \\
\text { considered "outer zone". Used to determine } \\
\text { developments allowed. }\end{array}$ & [60] \\
\hline & $\begin{array}{l}\text { States of Sao Paulo and Rio Grande do } \\
\text { Sul, Brazil }\end{array}$ & New, fixed installations & [27] \\
\hline & UK London Underground & $\begin{array}{l}\text { Rail customers, ALARP analysis above value and } \\
\text { broadly acceptable below value }\end{array}$ & {$[46]$} \\
\hline & Hungary & & {$[27]$} \\
\hline & IMO & $\begin{array}{l}\text { Passengers and public ashore and target values for } \\
\text { new ships }\end{array}$ & {$[48]$} \\
\hline \multirow[t]{2}{*}{$3 \times 10^{-7}$} & NFPA 59A & No restrictions & {$[8]$} \\
\hline & UK HSE & $\begin{array}{l}\text { Higher than this, considered "outer zone". Lower, } \\
\text { considered negligible and no restrictions. Used to } \\
\text { determine developments allowed. }\end{array}$ & {$[60]$} \\
\hline $1 \times 10^{-7}$ & Belgium & Border of area containing vulnerable location & [49] \\
\hline $1.4 \times 10^{-8}$ & $\begin{array}{l}\text { New Jersey Air Quality Permitting } \\
\text { Program }\end{array}$ & Cancer risk & {$[27]$} \\
\hline
\end{tabular}




\section{Abbreviations and Acronyms}

\begin{tabular}{|c|c|}
\hline ACRONYMS & EXPLANATION \\
\hline AA & Advise Against \\
\hline AIChE & American Institute of Chemical Engineers \\
\hline AAR & Association of American Railroads \\
\hline ALARP & As Low as Reasonably Practicable \\
\hline AIR & Average Individual Risk \\
\hline BLEVE & Boiling Liquid Expanding Vapor Explosion \\
\hline CCPS & Center for Chemical Process Safety \\
\hline $\mathrm{CNG}$ & Compressed Natural Gas \\
\hline CPR & Commissie Preventie van Rampen \\
\hline DOT & Department of Transportation \\
\hline DAA & Don't Advise Against \\
\hline $\mathrm{EU}$ & European Union \\
\hline FRA & Federal Railroad Administration \\
\hline FSA & Formal Safety Assessment \\
\hline HSE & Health and Safety Executive \\
\hline IR & Individual Risk \\
\hline IMO & International Maritime Organization \\
\hline ISO & International Organization for Standardization \\
\hline IPORBM & $\begin{array}{l}\text { Inter Province Committee for Risk Calculation } \\
\text { Methodology }\end{array}$ \\
\hline IIFR & Involuntary Individual Fatality Risk \\
\hline LNG & Liquefied Natural Gas \\
\hline MIACC & Major Industrial Accidents Council of Canada \\
\hline NASA & National Aeronautics and Space Administration \\
\hline NFPA & National Fire Protection Association \\
\hline NPP & Nuclear Power Plant \\
\hline NRC & Nuclear Regulatory Commission \\
\hline PHMSA & Pipeline and Hazardous Material Administration \\
\hline QRA & Quantitative Risk Assessment \\
\hline
\end{tabular}




\section{ACRONYMS EXPLANATION}

Safeti

Software for the Assessment of Flammable,

Explosive and Toxic Impact

UK

United Kingdom 